\title{
Enhanced characterisation for the management of industrial steel processing by products: potential of sequential chemical extraction
}

\author{
Kiri J. Rodgers • Iain S. McLellan • \\ Simon J. Cuthbert • Andrew S. Hursthouse $\mathbb{D}$
}

Received: 19 June 2018 / Accepted: 28 January 2019 / Published online: 27 February 2019

(C) The Author(s) 2019

\begin{abstract}
There is a pressing need for innovative waste management approaches as environmental regulations become more stringent worldwide alongside increasing demand for a more circular economy. Sequential chemical extraction (SE) analysis, which has previously been applied to environmental media such as soils and sediments, offers the potential to provide an understanding of the composition of solid steel processing by products, aiding the waste classification process and improving environmental protection. The definition of seven-phase associations through a SE method evaluated in this study were for (1) water soluble, (2) ion exchangeable, (3) carbonate, (4) amorphous Fe-Mn oxides, (5) crystalline Fe-Mn oxides, (6) sulphides and (7) silicate residues. Steel waste by-products (flue dust and filter cake) were evaluated for both extracted components (ICP analysis) and residual phases (using powder Xray diffraction, SEM and FTIR), to model the transformations taking place during extraction. The presence and removal of important potentially toxic element (PTE) host solid phases were confirmed during extraction. The SE protocol provides key information, particularly for the association of potentially toxic elements
\end{abstract}

K. J. Rodgers · I. S. McLellan · S. J. Cuthbert •

A. S. Hursthouse $(\bowtie)$

School of Science \& Sport, University of the West of Scotland, Paisley PA1 2BE, UK

e-mail: andrew.hursthouse@uws.ac.uk

A. S. Hursthouse

Hunan Regional Key Laboratory for Shale Gas Resource

Exploitation, Xiangtan, Hunan Province, China with the first three extracts, which are most sensitive in waste management processes. The water-soluble phase is the most available followed by ion-exchangeable and carbonate fractions, all representing phases more sensitive to environmental change, in particular to $\mathrm{pH}$. This study demonstrates that the distribution of potentially toxic elements such as zinc, lead and copper between sensitive and immobile phases can be reliably obtained in technological process by-products. We demonstrate that despite heterogeneity as a major variable, even for fine particulate matter, SE can provide more refined classification with information to identify reuse potential and ultimately minimise hazardous waste streams.

Keywords Sequential chemical extraction - Metal process by products $\cdot$ Waste management $\cdot$ Hazardous waste

\section{Introduction}

Waste management regulations worldwide are becoming more stringent, and the option to landfill wastes is being increasingly reduced (CEWEP 2012; Cointreau 2008; World Steel Association 2014). As a result, industrial operators from steel production or mining are faced with a critical need to assess their waste generation and the sustainability of current production processes. The amount of waste being generated can corrupt the production process infrastructure and can also cause environmental damage and breach regulatory thresholds. This adds to financial operating costs and causes 
us to question the sustainability of the production processes. The core aim of this study was to investigate the potential of chemical extraction procedures to improve waste characterisation and evaluate implications to improve management practice within the steel industry life cycle. Sequential chemical extraction (SE), which is a technique previously widely applied to study metal associations within soils and sediments, is utilised to fractionate the chemical composition of solid wastes in order to provide material characterisation in a robust approach and an alternative to the application of multiple analytical techniques, e.g. SEM, XRD, pseudo-total digestions and FTIR. In addition, the opportunity to learn more about elemental associations supports the development of sustainable processes and a more circular economy within the steel industry: through stabilisation and reclassification of commercially valuable elements which could be re-used within the production line, reducing waste and therefore costs to an industrial operation.

Sequential extraction

Sequential chemical extractions are widely used to operationally classify metals and potentially toxic elements (PTEs) in solid phases by their associations with discrete extraction phases or reactive fractions in solids media. Additionally, these extractions can be used as models to simulate various environmental scenarios, offering an insight to reactivity if material exposure occurs to sensitive receptors or surrounding conditions change with implications for wider environmental risk.

The two most commonly applied SE procedures are referred to as the BCR (Community Bureau of Reference) (Bacon et al. 2005) and Tessier (Tessier et al. 1979); however, both procedures have limitations when applied to industrial wastes, e.g. the BCR method has been reported to show misclassification for $\mathrm{Zn}$ during the first step and $\mathrm{Cu}$ in the second step when compared to certified materials for slags (Prudent et al. 1996), sediments (Zhan and Guo 2013, Cantario et al. 2012) and mining waste (Bacon and Davidson 2008), whereas Tessier's procedure requires constant modifications dependent on sample matrix particularly with regard to $\mathrm{pH}$ (Filgueiras et al. 2002). Although there is some bias towards these operating procedures, the application of SE has not been widely assessed for industrial wastes even though its potential has been demonstrated (Rodgers et al. 2015). The value of SE lies in its efficiency to characterise the mobility of PTEs in waste that in turn determines hazard potential which can then be assessed for future treatment/stabilisation options for materials. Previous studies have identified key characteristics of technological materials such as high proportion of metal constituents (Bacon and Davidson 2008) particle size and $\mathrm{pH}$ variation which can provide opportunities for comparative use of SE. For example in relation to mine wastes, Leinz et al. (2000) developed a seven-step series of extractions associated with operationally defined phases: water soluble, ion exchangeable, carbonate, amorphous Fe-oxide, crystalline Feoxide, sulphide and silicate.

This approach is particularly relevant for wastes from steel manufacturing, where the ability to distinguish between amorphous and crystalline $\mathrm{Fe}-\mathrm{Mn}$ oxides and sulfide bounds forms which exhibit varying reactivity and environmental sensitivity given our current understanding of phase associations of PTEs in these waste materials presents useful fractionation information supporting waste management options. Furthermore, this can help reduce overly conservative allocation of waste to hazardous categories and improve sustainability of industrial operations.

In this study, we evaluated the seven-step methodology applied to a number of typical steel production byproducts. These include flue dust (FD) produced in significant quantities from dust-laden fumes of the steel-making process which utilise large amounts of oxygen in production. For example, dust can be expelled from the top of the blast furnace during smelting or during compaction in the sintering process. These dusts are collected using a range of techniques and leads to the generation by-product from the basic oxygen furnace (BOF) and the filter cake (FC), which is the material produced from the filtering process in gas cleaning systems.

As previous experimental studies have shown procedural adjustments may be required to adapt to the different physico-chemical properties of steel wastes (Rodgers et al. 2015), the potential of SE was explored and a method validation exercise undertaken to provide practical assessment of application. The approach described here uses additional solid-phase analysis (SPA) techniques, e.g. solid-phase identification where suitable by X-ray diffraction (XRD), elemental distribution in prepared samples by scanning electron microscopy (SEM) and active functional groups - particularly metal oxides, carbonates and other carbon-containing 
functional groups by Fourier transform infrared spectroscopy (FTIR), to provide various characteristic information, e.g. key functional groups or mineral phases, to model the PTE partitioning and extraction during the application of the seven-step protocol.

\section{Experimental}

\section{Sequential extraction}

Samples were supplied from a steel company, air dried, sieved to less than $2 \mathrm{~mm}$, mixed, cone and quartered (IUPAC 2017) before being weighed out for experimentation (Table 1). The theoretical reactivity is briefly summarised in a table of predicted chemical reactivity during each step (Table 2), providing context for assessment of each extraction step and interpretation of data from solid and liquid phases.

\section{Reagents}

All chemical reagents were obtained from Fisher Scientific (Loughborough, UK) or Sigma-Aldrich (Gillingham, Dorset, UK) and were of analytical grade, unless otherwise stated. Deionised water was used for all applications unless otherwise stated, in which case ultrahigh purity water (ELGA Process Water, resistivity $\geq$ 18.2 $\mathrm{M} \Omega \mathrm{cm}^{-1}$ ) was used. An appropriate certified reference material (EURO STANDARD 877/1 steel furnace dust) (CRM) was used to check analytical accuracy for elemental determination.

Instrumentation (ICP-AES)

Aqueous elemental concentrations were determined using inductively coupled plasma atomic emission spectrometry (ICP-AES) (Thermo iCAP 6000 series), with instrumental configuration as outlined in Tables 3 and 4. Samples in non-acidic matrices (i.e. $\mathrm{pH}>2$ ) were preserved until analysis by acidification using $\mathrm{HNO}_{3}(1 \%$ $v / v)$ and were calibrated with three matrix-matched mixed elemental calibration standards $(0 \mathrm{mg} / 1,2 \mathrm{mg} / \mathrm{l}$ and $10 \mathrm{mg} / \mathrm{l})$. Procedural blanks were prepared with each sample batch, and were treated as per the samples, all of which were run in triplicate.

For quality assurance and quality control (QA/ QC) purposes, the most sensitive wavelengths were selected for elemental determination based on their Wohlers value (Todorov et al. 2014); following analysis, the values for each wavelength were compared to check for potential interferences. If no known interference was identified, a wavelength was visually selected based on peak shape (i.e. most Gaussian shaped) and intensity (the peak with the greatest intensity). There were noticeable difficulties when analysing for nickel in the sequential extraction procedure which were caused by interferences from not only $\mathrm{Si}$ at $221.6 \mathrm{~nm}$ but also $\mathrm{Cr}$ and $\mathrm{Fe}$ at $232 \mathrm{~nm}$ (Inorganic Ventures 2016), as this could not be resolved $\mathrm{Ni}$ was omitted from analysis. The

Table 1 Summary of sequential extraction method

\begin{tabular}{|c|c|c|c|}
\hline Step & Phase & Reagent & Description of procedure \\
\hline 1 & Water soluble & $\begin{array}{l}0.25 \mathrm{~g} \text { sample, with } 0.25 \mathrm{~g} \text { silica gel } \\
\text { and } 25 \mathrm{ml} \text { deionised water }\end{array}$ & $\begin{array}{l}\text { Reagents mixed in a } 50 \mathrm{ml} \text { centrifuge tube for } 2 \mathrm{~h} \\
\text { in a horizontal, reciprocating shaker. }\end{array}$ \\
\hline 2 & Ion exchangeable & $25 \mathrm{ml} 1 \mathrm{M}$ sodium acetate & $\begin{array}{l}\text { Residue extracted for } 1 \mathrm{~h} \text { in a horizontal } \\
\text { reciprocating shaker, at ambient temperature. }\end{array}$ \\
\hline 3 & Carbonate associated & $\begin{array}{l}25 \mathrm{ml} 1 \mathrm{M} \text { sodium acetate buffered to } \\
\mathrm{pH}<5 \text { with acetic acid }\end{array}$ & Shaken for $2 \mathrm{~h}$ \\
\hline 4 & $\mathrm{FeOX}_{\mathrm{am}}$ & $\begin{array}{l}25 \mathrm{ml} \text { hydroxylamine hydrochloride } \\
\text { in } 0.25 \mathrm{M} \mathrm{HCl}\end{array}$ & Residue is extracted for $30 \mathrm{~min}$ in a water bath at $50{ }^{\circ} \mathrm{C}$ \\
\hline 5 & $\mathrm{FeOX}_{\text {cryst }}$ & $25 \mathrm{ml} 4 \mathrm{M} \mathrm{HCl}$ & 30 min water bath at $94{ }^{\circ} \mathrm{C}$ \\
\hline 6 & Sulphide & $\begin{array}{l}\text { 1st extract: } 2 \text { g of sodium chlorate }+10 \mathrm{ml} \\
\text { conc } \mathrm{HCl} \text {. Then deionised water (DI) } \\
\text { 2nd extract: } 25 \mathrm{ml} 4 \mathrm{M} \mathrm{HNO}_{3}\end{array}$ & $\begin{array}{l}\text { Initial reagents added over } 45 \mathrm{~min} \text {, extracted and then } \\
\text { diluted to } 25 \mathrm{ml} \text {. Residue is then extracted for a further } \\
\text { 40mins in a boiling water bath. The two extracts are } \\
\text { analysed separately and results are combined. }\end{array}$ \\
\hline 7 & Residual/silicate & Aqua regia $\left(\mathrm{HCl}: \mathrm{HNO}_{3}\right)$ & $\begin{array}{l}\text { Residue transferred to a Teflon beaker and is } \\
\text { digested with aqua regia }\end{array}$ \\
\hline
\end{tabular}




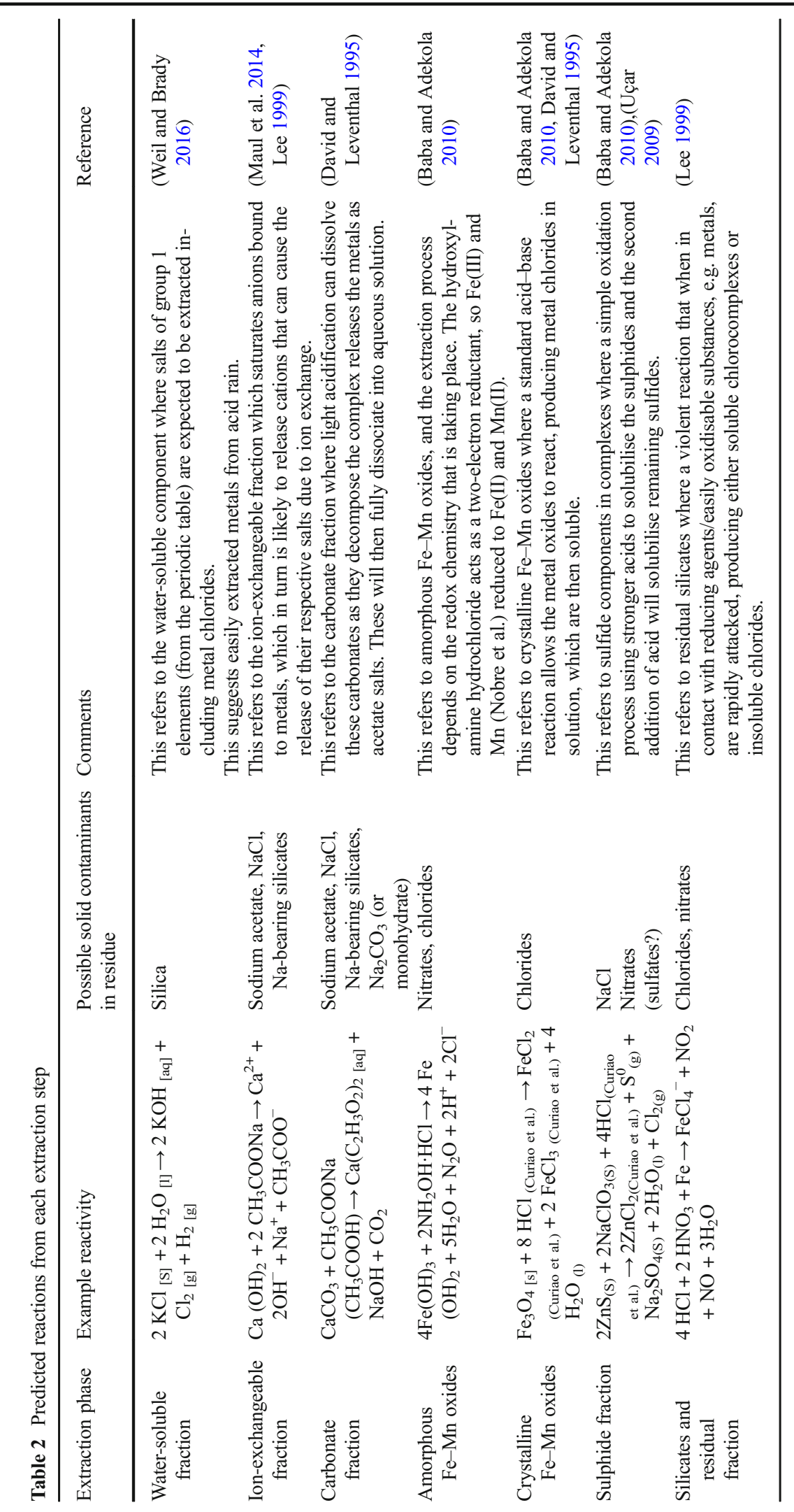


Table 3 Instrumental configuration conditions (ICP-AES)

\begin{tabular}{ll}
\hline Parameter & ICP-AES \\
\hline Matrix & Total digests and SEP extracts \\
Nebuliser gas & Argon \\
Collision cell gas flow & $\mathrm{n} / \mathrm{a}$ \\
Power & $1.40 \mathrm{~kW}$ \\
Coolant flow & $12 \mathrm{l} / \mathrm{min}$ \\
Plasma flow & $15 \mathrm{l} / \mathrm{min}$ \\
Nebuliser flow & $1.01 / \mathrm{min}$ \\
Nebuliser & Glass concentric \\
Auxiliary flow & $1.51 / \mathrm{min}$ \\
Viewing height & $8 \mathrm{~mm}$
\end{tabular}

$n / a$ not available

wavelengths used for analysis were as follows: $\mathrm{Cr}$ $205.562 \mathrm{~nm}, \mathrm{Cu} 327.400 \mathrm{~nm}, \mathrm{Mn} 257.606 \mathrm{~nm}, \mathrm{~Pb}$ $22.354 \mathrm{~nm}$ and $\mathrm{Zn} 206.198 \mathrm{~nm}$.
Powder X-ray diffraction

Samples were prepared by crushing to $<20 \mu \mathrm{m}$ then evenly filled into an aluminium sample holder (PMMA $0.49 \mathrm{~mm}$ diameter). Samples were analysed by a Siemens D5000 diffractometer, and the instrument was calibrated using a silica standard and was configured with a $\mathrm{Cu} \mathrm{K} \alpha$ radiation source. X-ray diffraction patterns were collected from a $2 \theta$ operating range with a 1 to $75^{\circ}$ and $0.01^{\circ} \mathrm{s}^{-1}$ angle interval/dwell time.

The baseline was subtracted from resulting diffractograms and smoothed before being compared with diffraction pattern libraries for phase identification, using the EVA software package (DIFFRACplus suite, Burker Corporation) and ICCD (The international centre for diffraction data 1997-2015). These subtractions were carried out as a result of characteristic "humps" being observed, caused by amorphous structures within the waste sample matrices, and from additional

Table 4 ICP-AES analytical wavelength interferences caused by metal rich processing by product components identified

\begin{tabular}{|c|c|c|c|c|c|}
\hline \multirow[t]{2}{*}{ Element } & \multicolumn{3}{|c|}{ Wavelength (nm) } & \multirow[t]{2}{*}{ Interference } & \multirow[t]{2}{*}{ Caused by: } \\
\hline & 1 & 2 & 3 & & \\
\hline $\mathrm{Al}$ & 396.147 & 394.396 & 308.211 & $\mathrm{~N}$ & - \\
\hline B & 249.776 & 208.885 & - & $\mathrm{Y}$ & $\mathrm{Fe}-249.772 \mathrm{~nm}$ \\
\hline $\mathrm{Ba}$ & 233.519 & 455.408 & - & $\mathrm{N}$ & - \\
\hline $\mathrm{Be}$ & 313.107 & 313.049 & - & $\mathrm{Y}$ & $*$ \\
\hline $\mathrm{Bi}$ & 223.057 & 190.174 & - & $\mathrm{N}$ & - \\
\hline $\mathrm{Ca}$ & 317.938 & 422.666 & 315.888 & $\mathrm{~N}$ & - \\
\hline $\mathrm{Cd}$ & 228.798 & 241.436 & - & $\mathrm{Y}$ & As $-214.410 \mathrm{~nm}$ \\
\hline Co & 228.611 & 238.895 & 230.782 & $\mathrm{Y}$ & $\mathrm{Fe}-238.863 \mathrm{~nm}$ \\
\hline $\mathrm{Cr}$ & 267.716 & 205.562 & 357.863 & $\mathrm{~N}$ & - \\
\hline $\mathrm{Cu}$ & 327.4 & 324.749 & - & $\mathrm{Y}$ & $\mathrm{Fe}-324.7 .28 \mathrm{~nm}$ \\
\hline $\mathrm{Fe}$ & 238.2 & 239.565 & 259.936 & $\mathrm{~N}$ & \\
\hline $\mathrm{K}$ & 766.494 & - & - & $\mathrm{N}$ & - \\
\hline $\mathrm{Li}$ & 670.784 & 610.351 & - & $\mathrm{Y}$ & $\mathrm{Ca}-610.272 \mathrm{~nm}$ \\
\hline $\mathrm{Mg}$ & 285.217 & 279.074 & - & $\mathrm{N}$ & - \\
\hline $\mathrm{Mn}$ & 257.606 & 260.564 & - & $\mathrm{N}$ & - \\
\hline $\mathrm{Na}$ & 589.583 & 588.983 & - & $\mathrm{Y}$ & $*$ \\
\hline $\mathrm{Ni}$ & 231.606 & 232.006 & 221.65 & Y & $\mathrm{Fe}-232.036 \mathrm{~nm} ; \mathrm{Mo}-221.66 \mathrm{~nm}$ \\
\hline $\mathrm{Pb}$ & 216.996 & 220.354 & - & $\mathrm{Y}$ & $\mathrm{Fe}-216.995 \mathrm{~nm}$ \\
\hline $\mathrm{Ti}$ & 334.937 & 336.114 & - & $\mathrm{Y}$ & $\mathrm{Ca}-336.192 \mathrm{~nm}$ \\
\hline $\mathrm{Tl}$ & 190.801 & 276.787 & - & $\mathrm{N}$ & - \\
\hline $\mathrm{V}$ & 310.233 & 292.407 & 309.313 & $\mathrm{Y}$ & $\mathrm{Al}-309.271 \mathrm{~nm}$ \\
\hline $\mathrm{Zn}$ & 206.198 & 213.858 & 202.548 & $\mathrm{~N}$ & \\
\hline
\end{tabular}


fluorescence that can be attributed to the Fe-rich matrix. The addition of a nickel "filter" helped to significantly reduce the amount of fluorescence and intensity of the $\mathrm{K} \beta$ lines generated in the spectrum (Suryanarayana and Norton 1998) improving resolution and phase identification.

\section{Fourier-transform infrared spectroscopy}

Thermo Scientific Nicolet 6700 FTIR spectrometer was used for analysis and carried out at room temperature. Air-dried solid samples were analysed on the single reflection ATR (attenuated total reflectance) mode for its robustness and durability. The crystal area was cleaned, the background collected and then the powdered sample was placed onto the small crystal area (with the sample height less than a few millimetres) and scanned between 300 and $4000 \mathrm{~nm}$ for a total of 64 scans. Both raw and ground samples were analysed for comparison.

\section{Scanning electron microscopy}

A Hitachi S4100 field emission SEM was used to run samples at $20 \mathrm{kV}$ and a 15 -mm working distance using a germanium detector. Typical sample preparation involved mounting a sample onto a "stub" with double sided tape; commonly, electrically conductive carbon is used or by impregnation in an epoxy resin mould. For both approaches, the samples are then coated with an electrically conductive material, i.e. carbon or gold using a sputter coater to reduce charging potential during analysis. These approaches were less successful due to excessive charging or inability to mix into an epoxy resin as a result of the samples high hydrophobic nature.

Therefore, the method development used to overcome these issues utilised a $\mathrm{KBr}$ press for the purpose of compacting the particulates together to form a pellet (Fig. 1). Each sample (approximately $200 \mathrm{mg}$-more for finer particulate) was pressed (with no addition of $\mathrm{KBr}$ ) into a cleaned press to avoid $\mathrm{K}$ or $\mathrm{Br}$ contamination. These pellets were then additionally impregnated using an epoxy resin mixture (EPO-TEX) into moulds, where the air was removed using a Logitech impregnation Unit IU30, before being left to cure and once set the mould was cut in half and reset to obtain cross sections of the pellet.

Specimen samples were prepared in this manner to stabilise the specimen, i.e. avoid fine particle sputtering

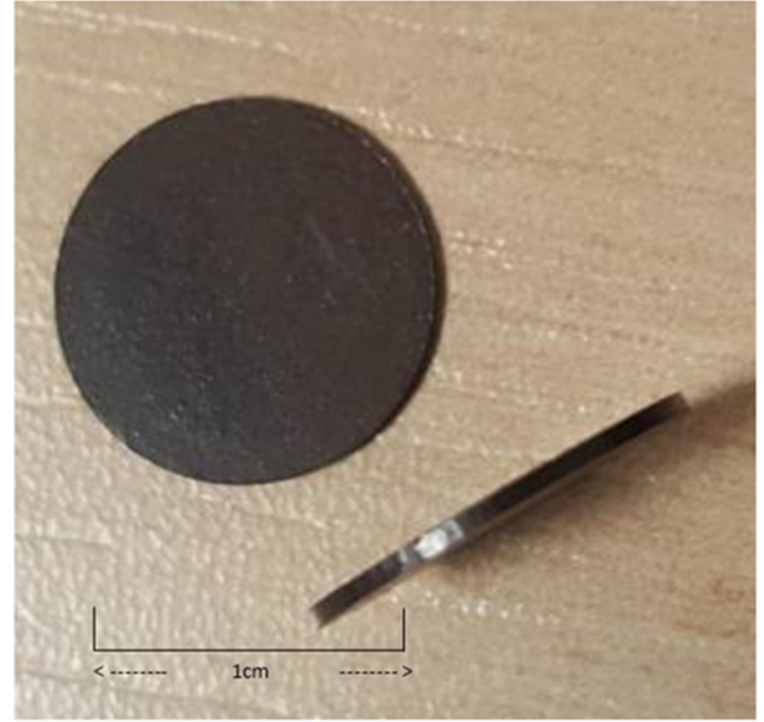

Fig. 1 Waste samples contained in pressed $\mathrm{KBr}$ pellet

caused by charging, which is particularly problematic for the finer particles, even when being gold coated, and reduce the amount of handling of the specimen.

The majority of samples analysed were coated in gold, with a subset coated in carbon. This was because gold has a high electron output for secondary electrons and can keep the sample grounded electronically and mechanically for analysis. It needs to be acknowledged that this approach can greatly reduce the size of low energy peaks as a result of gold's large mass and the subsequent intensity ratio. Alternatively, when carbon coating was used, a higher sensitivity for lower energy peaks was achieved; however, this can skew its own identification and charging can occur after longer analysis periods, i.e. for mapping. Both coating applications were applied to distinguish between sample compositions, particularly with regard to carbon (C) and low abundance elements.

\section{Results}

Pseudo-total PTE content

Initial characterisation was carried out for the two samples (FD and FC) as well as the CRM with FD and FC results shown in (Tables 5 and 6) and CRM recoveries of $96-104 \%$. These values can be used as baseline comparisons for SE and SPA. 
Table 5 Pseudo-total analysis results for PTEs in flue dust

\begin{tabular}{|c|c|c|c|c|c|}
\hline & Mean (ppm) & STDEV & Mean \% & Oxide & \\
\hline $\mathrm{Al}$ & $8,163.6$ & 859.0 & 0.8164 & 3.09 & $\mathrm{Al}_{2} \mathrm{O}_{3}$ \\
\hline As & 3.419 & 1.661 & 0.0003 & & \\
\hline $\mathrm{Ba}$ & 157.04 & 16.384 & 0.0157 & & \\
\hline $\mathrm{Be}$ & 0.486 & 0.047 & 0.0000 & & \\
\hline $\mathrm{Bi}$ & 0 & 0 & 0.0000 & & \\
\hline $\mathrm{Ca}$ & 694,881 & 72,301 & 69.4 & 97.2 & $\mathrm{CaO}$ \\
\hline $\mathrm{Co}$ & 1.175 & 0.391 & 0.0001 & & \\
\hline $\mathrm{Cr}$ & 345.15 & 16.78 & 0.0345 & & \\
\hline $\mathrm{Cu}$ & 209.2 & 7.435 & 0.021 & & \\
\hline $\mathrm{Fe}$ & 9549 & 348.40 & 0.955 & 2.73 & $\mathrm{Fe}_{2} \mathrm{O}_{3}$ \\
\hline $\mathrm{K}$ & 16,268 & 728.99 & 1.6268 & & \\
\hline $\mathrm{Li}$ & 89.235 & 3.368 & 0.009 & & \\
\hline $\mathrm{Mg}$ & $6,960.2$ & 224.2 & 0.696 & 1.15 & $\mathrm{MgO}$ \\
\hline $\mathrm{Mn}$ & 804.8 & 29.451 & 0.0805 & & \\
\hline $\mathrm{Na}$ & $8,000.6$ & 305.828 & 0.8001 & 2.16 & $\mathrm{Na}_{2} \mathrm{O}$ \\
\hline $\mathrm{Ni}$ & 123.67 & 4.639 & 0.0124 & & \\
\hline $\mathrm{Pb}$ & 46.968 & 4.809 & 0.0047 & & \\
\hline $\mathrm{Sb}$ & 0 & 0 & 0.0000 & & \\
\hline $\mathrm{Se}$ & 436.68 & 30.83 & 0.0437 & & \\
\hline $\mathrm{Sr}$ & 521.8 & 19.91 & 0.0522 & & \\
\hline $\mathrm{Ti}$ & 31.94 & 2.95 & 0.0032 & & \\
\hline $\mathrm{Tl}$ & 0 & 0 & 0.0000 & & \\
\hline V & 6.562 & 0.444 & 0.0007 & & \\
\hline $\mathrm{Zn}$ & 45.832 & 1.991 & 0.0046 & & \\
\hline Total & & & 74.66 & 106.33 & \\
\hline
\end{tabular}

$\mathrm{Si}, \mathrm{C}, \mathrm{S}, \mathrm{O}$ and $\mathrm{H}$ were not analysed, and therefore, oxides below assume stoichiometry with oxygen and iron is presumed ferric. Elements for which the oxide exceeds $1 \mathrm{wt} \%$ are $\mathrm{Al}, \mathrm{Ca}, \mathrm{Fe}, \mathrm{Mg}$ and $\mathrm{Na}$. $\mathrm{Ca}$ is predominant at $>97 \%$ oxide, indicative of lime, $\mathrm{Ca}-$ silicate and/or carbonates.

\section{Sequential extraction}

The sequential extraction procedure (SEP) (Table 1) was applied to 20 replicates of a certified reference material (CRM), flue dust (FD) and filter cake (FC) with data summarised below (Figs. 2, 3, 4, 5, 6 and 7 inclusive). We focus on the following potentially toxic elements (PTEs) of particular interest: $\mathrm{Cr}, \mathrm{Cu}, \mathrm{Mn}, \mathrm{Pb}$ and $\mathrm{Zn}$. These elements have been highlighted as key constituents that can cause problems within the steel production process as well as having the potential to pollute the surrounding environment, for example $\mathrm{Zn}$ and $\mathrm{K}$ baring carbonates can damage and weaken the lining of the blast furnace's lining (Besta et al. 2013, 2014).
Table 6 Pseudo-total analysis results for PTEs in filter cake

\begin{tabular}{|c|c|c|c|c|c|}
\hline & Mean (ppm) & STDEV & Mean \% & Oxide & \\
\hline $\mathrm{Al}$ & 820.51 & 81.478 & 0.0821 & & \\
\hline As & 9.57 & 2.283 & 0.0010 & & \\
\hline $\mathrm{Ba}$ & 43.793 & 4.387 & 0.0044 & & \\
\hline $\mathrm{Be}$ & 0.056 & 0.02 & 0.0000 & & \\
\hline $\mathrm{Bi}$ & 0 & 0 & 0.0000 & & \\
\hline $\mathrm{Ca}$ & 341,562 & 36,173 & 34.16 & 47.79 & $\mathrm{CaO}$ \\
\hline $\mathrm{Co}$ & 607.227 & 41.485 & 0.0607 & & \\
\hline $\mathrm{Cr}$ & 38,214 & 3902.7 & 3.821 & 11.17 & $\mathrm{Cr}_{2} \mathrm{O}_{3}$ \\
\hline $\mathrm{Cu}$ & 2019.6 & 206.67 & 0.202 & & \\
\hline $\mathrm{Fe}$ & 203,741 & 17,444 & 20.37 & 58.3 & $\mathrm{Fe}_{2} \mathrm{O}_{3}$ \\
\hline $\mathrm{K}$ & 0 & 0 & 0.0000 & & \\
\hline $\mathrm{Li}$ & 0.352 & 0.032 & 0.0000 & & \\
\hline $\mathrm{Mg}$ & 2620.3 & 277.2 & 0.2620 & & \\
\hline $\mathrm{Mn}$ & 4658.276 & 490.315 & 0.4658 & & \\
\hline $\mathrm{Na}$ & 3979.2 & 293.35 & 0.397 & 1.07 & $\mathrm{Na}_{2} \mathrm{O}$ \\
\hline $\mathrm{Ni}$ & 36,060 & 3566 & 3.60 & 4.6 & $\mathrm{NiO}$ \\
\hline $\mathrm{Pb}$ & 695.221 & 62.254 & 0.0695 & & \\
\hline $\mathrm{Sb}$ & 151.09 & 14.744 & 0.0151 & & \\
\hline $\mathrm{Se}$ & 4373.277 & 365.316 & 0.4373 & & \\
\hline $\mathrm{Sr}$ & 141.828 & 10.304 & 0.0142 & & \\
\hline $\mathrm{Ti}$ & 49.437 & 4.03 & 0.0049 & & \\
\hline $\mathrm{Tl}$ & 0 & 0 & 0.0000 & & \\
\hline V & 142.159 & 12.245 & 0.0142 & & \\
\hline $\mathrm{Zn}$ & 220.41 & 20.153 & 0.0220 & & \\
\hline Total & & & 64.01 & 123.6 & \\
\hline
\end{tabular}

$\mathrm{Si}, \mathrm{C}, \mathrm{S}, \mathrm{O}$ and $\mathrm{H}$ were not analysed and therefore Oxides below assume stoichiometry with oxygen and Iron is presumed ferric. Elements for which the oxide exceeds 1 wt $\%$ are $\mathrm{Ca}, \mathrm{Cr}, \mathrm{Fe}, \mathrm{Na}$ and $\mathrm{Ni}$. The oxide total is very high, so Fe is most likely in not only a ferrous form but also as the predominant cation along with $\mathrm{Ca}$.

\section{Certified reference material}

No steel processing by-product reference materials are commercially available for SE. The use of the furnace dust CRM (EURO STANDARD ECRM-B $877 / 1$ ) provides an opportunity to identify the scope of analytical method development by comparing its certified total concentrations with the cumulative pseudo-total concentrations from the $\mathrm{SE}$ steps. Figure 2 shows the distribution of the key PTEs ( $\mathrm{Cr}, \mathrm{Cu}, \mathrm{Mn}, \mathrm{Pb}$ and $\mathrm{Zn}$ ) across the various fractions, and Fig. 3 shows the variation between replicates. There was insufficient solid residue left to perform a digest of the final residual fractions but the cumulative total of the six 
Fig. 2 Elemental distribution in CRM 877-1 furnace dust. PTEs (normalised to $100 \%$ ) across seven SE steps. Pseudo-totals: $\mathrm{Zn}$ $10,108 \mathrm{mg} / \mathrm{kg}, \mathrm{Pb} 10,084 \mathrm{mg} / \mathrm{kg}$, $\mathrm{Mn} 11,208 \mathrm{mg} / \mathrm{kg}, \mathrm{Cu}$ $206.3 \mathrm{mg} / \mathrm{kg}, \mathrm{Cr} 113.2 \mathrm{mg} / \mathrm{kg}$

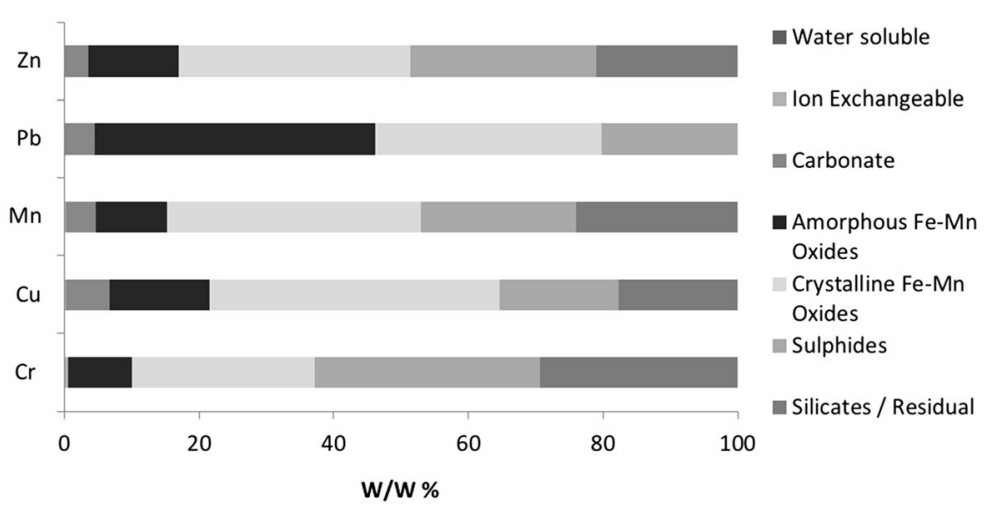

measured extracts resulted in recoveries $>80 \%$ (excluding $\mathrm{Cr}$ with 66\%).

The SE analysis of PTEs in the CRM extracts show the reproducibility of replicates for each extraction step (1-6 refers to ion exchangeable to sulphides). For example, fractions 3-6 show variability in concentration of less than $10 \%$. This is similar to the pseudo-total analysis with 6-9\% variation, which shows good reproducibility for the SE procedure. The first two extracts show higher variability, which is a consequence of low concentrations, i.e. close to, limit of detection (see above).

\section{Flue dust}

Results from the SEP applied to flue dust samples are shown in Fig. 4, with variability shown in Fig. 5. The FD samples vary most in the 1st fraction $32-189 \%$ RSD, which is symptomatic of the low concentrations and variable dissolution of these PTEs in weak reagents. The latter fractions (4-6) demonstrate higher PTE concentrations, with lower variation (4th $7-13 \%$, 5th $14-27 \%$ and 6th 15-40\%). There is a significantly large variation observed with regard to $\mathrm{Pb}$ and $\mathrm{Zn}$ found in the carbonate phase (196 and 225\% respectively).

\section{Filter cake}

Results from sequential extraction applied to filter cake samples are seen in Fig. 6 with variability shown in Fig. 7. The distribution of PTEs shows the predominant fraction for each PTE to be different; sulphides are the main phase associated with $\mathrm{Cr}$ and $\mathrm{Pb}$ (29\% and 33\%), $\mathrm{Cu}$ and $\mathrm{Mn}$ are predominantly linked to amorphous $\mathrm{Fe}-$ Mn oxides (24\% and 26\%) and finally the majority of $\mathrm{Zn}$ can be found in the residual fraction (54\%).

The filter cake samples have a much higher variation between replicate samples, which is likely to be a result of the high variation in production feed, i.e. scrap steel. The carbonate phase shows the highest variation between replicates with RSD values ranging from $40 \%$
Fig. 3 Variations between PTE concentrations from the SE extracts for CRM 877-1 furnace dust (1-water soluble, 2 -ion exchangeable, 3 - carbonates, 4-Fe-Mn oxides (amorphous), $5-\mathrm{Fe}-\mathrm{Mn}$ oxides (crystalline), 6 - sulfides). $n=20$. Error bars $=$ standard deviation

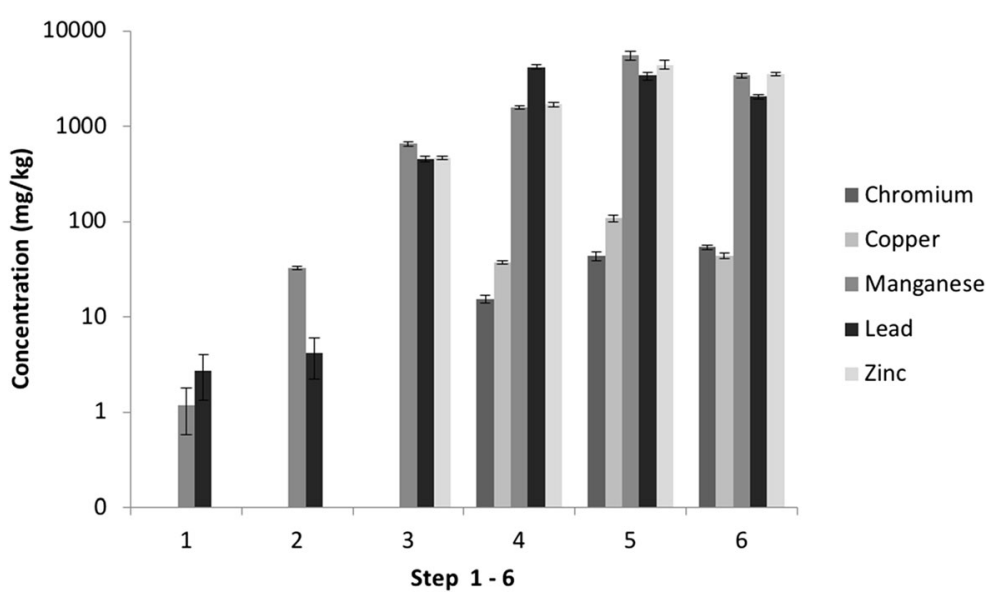


Fig. 4 Measured elemental distribution of PTEs found in flue dust samples determined by a seven-step SEP. Pseudo-totals: $\mathrm{Zn}$ $67.0 \mathrm{mg} / \mathrm{kg}, \mathrm{Pb} 45.8 \mathrm{mg} / \mathrm{kg}, \mathrm{Mn}$ $803.1 \mathrm{mg} / \mathrm{kg}, \mathrm{Cu} 209.2 \mathrm{mg} / \mathrm{kg}, \mathrm{Cr}$ $343.8 \mathrm{mg} / \mathrm{kg}$

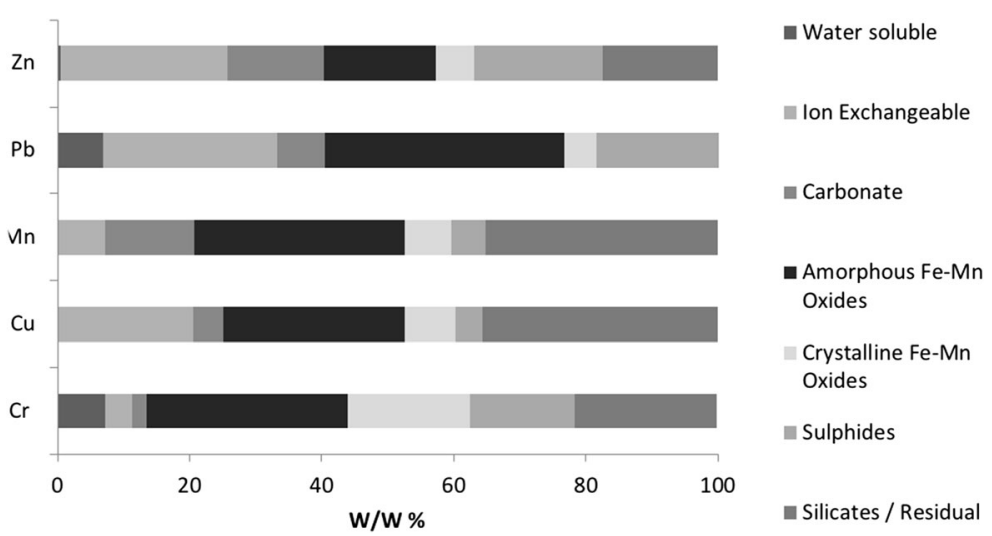

for Mn up to $225 \%$ for $\mathrm{Zn}$. This is likely to be indicative of the heterogeneous nature within the sample matrix and a variation in extraction success. The latter three fractions show a lower variation (\%RSD) but still notable to suggest a significant variation in replicates: Amorphous Fe-Mn oxides varies between 7 and 13\%, crystalline Fe-Mn oxides 14-27\% and sulphides 16-39\%. As a result, there is no evidence to suggest that the concentration of the sample influences the variation.

The model proposed for mineralogical hosts for the PTE is "probed" using routine solid-phase analysis techniques, and from the SEP results, there are a number of factors that need to be considered before assessing the success of extractions: The quantity of the final solid residuum ("residual fraction") shown in these results has been calculated by mass balance, which means that the concentrations of dissolved species in the first six extracts have been summed and subtracted from the pseudo-total concentration. As opposed to quoting the measured content from the residual step, for two reasons:

1- The results calculated and presented here do not take into account the sample loss that takes place between each SE step as a result of the transport and filtration processes but assumes the mass measured at the start. This means all of the extracted residues, particularly the final residuum, will have lower mass compared to their original weight, e.g. $0.2 \mathrm{~g}$ as opposed to $0.25 \mathrm{~g}$, which will result in a more conservative value obtained. This is a limitation common to all extraction procedures and can be minimised by good laboratory practice.

2- As a result of the larger variations found within the pseudo-total digestions (9-20\% in flue dust replicates and $16 \%$ in filter cake), the higher uncertainty generated in data means values can be either overly conservative or liberal.

Calculation of the residual content by difference compounds these uncertainties and should not be confused with the calculation used to express the individual distribution of each PTE. This involves their respective concentrations $(\mathrm{mg} / \mathrm{kg})$ as a percent of the sample pseudo-total value as an "\% w/w extracted". The high levels of calcite and portlandite in FD and the Fe-rich composition of FC give rise for recover concerns;
Fig. 5 Variations between PTE concentrations from the SE extracts of flue dust samples (1-water soluble, 2 - ion exchangeable, 3 - carbonates, 4-Fe-Mn oxides (amorphous), $5-\mathrm{Fe}-\mathrm{Mn}$ oxides (crystalline), 6-sulphides)

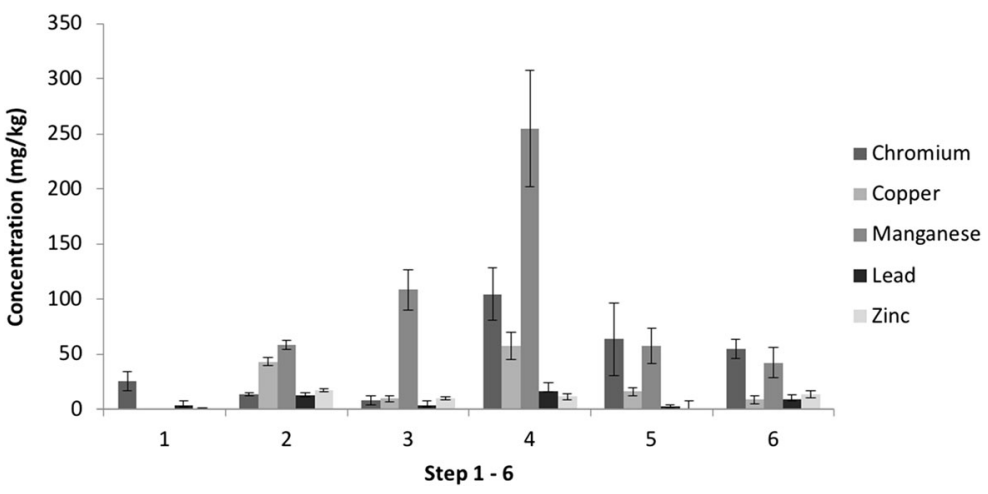


Fig. 6 Measured elemental distribution of PTEs found in filter cake samples. Pseudo-totals: $\mathrm{Zn} 37,471 \mathrm{mg} / \mathrm{kg}, \mathrm{Pb}$ $2010 \mathrm{mg} / \mathrm{kg}, \mathrm{Mn} 4688 \mathrm{mg} / \mathrm{kg}, \mathrm{Cu}$ $702.4 \mathrm{mg} / \mathrm{kg}$, Cr $22.60 \mathrm{mg} / \mathrm{kg}$

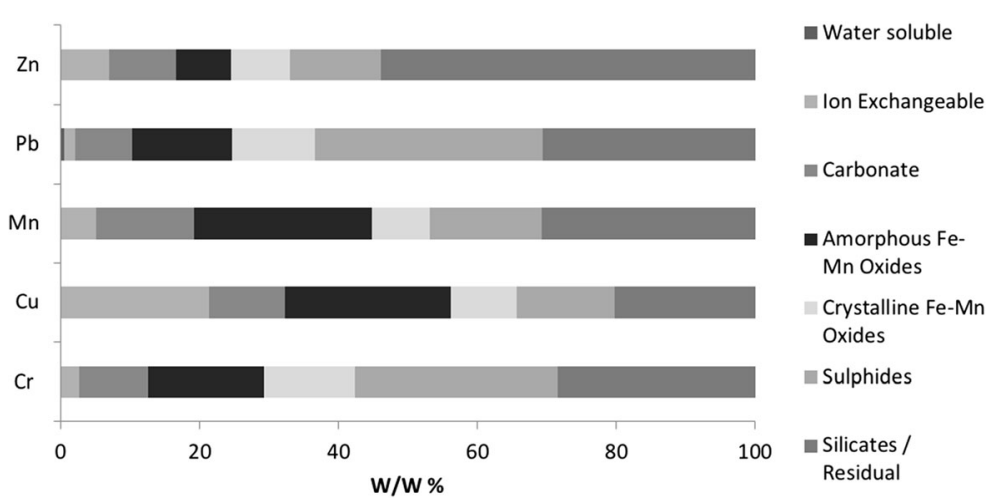

however, this approach proves successful dissolution with its total recovery.

Levels of chromium measured released from the sulphide fraction are also attributed to the sodium chromate that is added as an extracting reagent during this step. It is unlikely that there is $\mathrm{Cr}_{2} \mathrm{~S}_{3}$ in the steel wastes, particularly as initial characterisation was unable to identify the presence of this phase. However, whilst other oxidisable fractions could be present in the sample, they cannot be quantified due to masking by this exaction reagent.

\section{Solid-phase analysis}

To monitor structural changes at a molecular level between extraction steps, XRD, FTIR and SEM were used to analyse FD and FC solid residues, to identify, where possible, the effect of each extraction step during the sequential extraction process. The techniques predominantly identify changes (losses) of particular features, i.e. functional groups or crystalline compounds that inturn can be interpreted as phase losses. It is important to identify the use of "simple" and "common" analytical methods in this evaluation, making the technique more practical in application during waste management. Alternative approaches such as use of synchrotron radiation probes are acknowledged, but not in scope for this study.

\section{Powder X-ray diffraction}

Initial P-XRD analysis of both FD and FC sample characterisations was carried out using QualX-software using a polynomial to estimate the background and smoothing requirements as well as SEM elemental analysis for compositional filtering and initial mineralogical comparisons.

The mineralogical identifications made from the FD raw and residual fraction samples (the 6th extract) are shown in Figs. 8 and 9, for comparison (diffractograms from other steps are not included). The description of the phases identified between each extract can be found below, and some spectral lines are highlighted.

The flue dust (Fig. 8), d-traces (with $\mathrm{K} \alpha_{2}$ stripped out), shows a hump at the low two-theta end indicating a substantial amount of glass. The QualX-software matching process identified major phases to be portlandite and calcite, with a few percent fluorite, a
Fig. 7 Variations between PTE concentrations from the SE extracts of filter cake samples (1-water soluble, 2 -ion exchangeable, 3 - carbonates, 4- $\mathrm{Fe}-\mathrm{Mn}$ oxide amorphous, 5- $\mathrm{Fe}-\mathrm{Mn}$ oxides crystalline, 6 -sulfides)

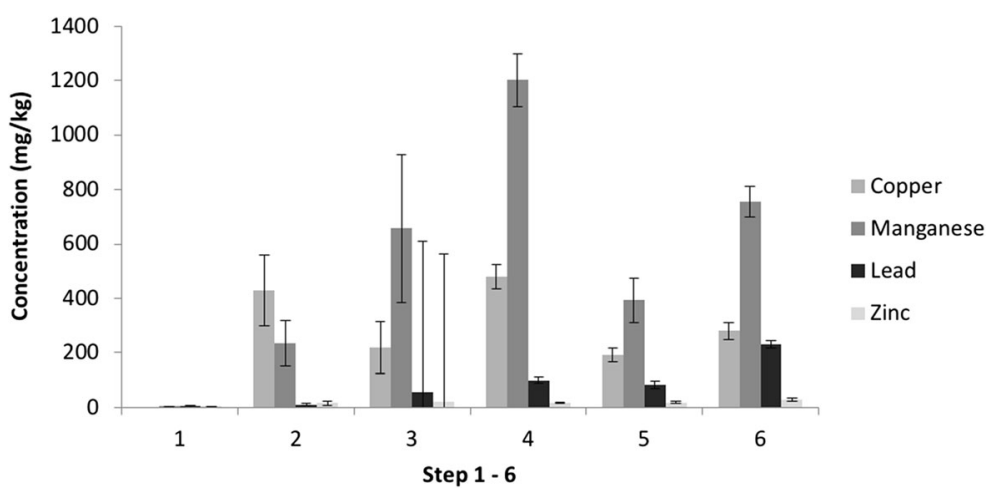


intensity

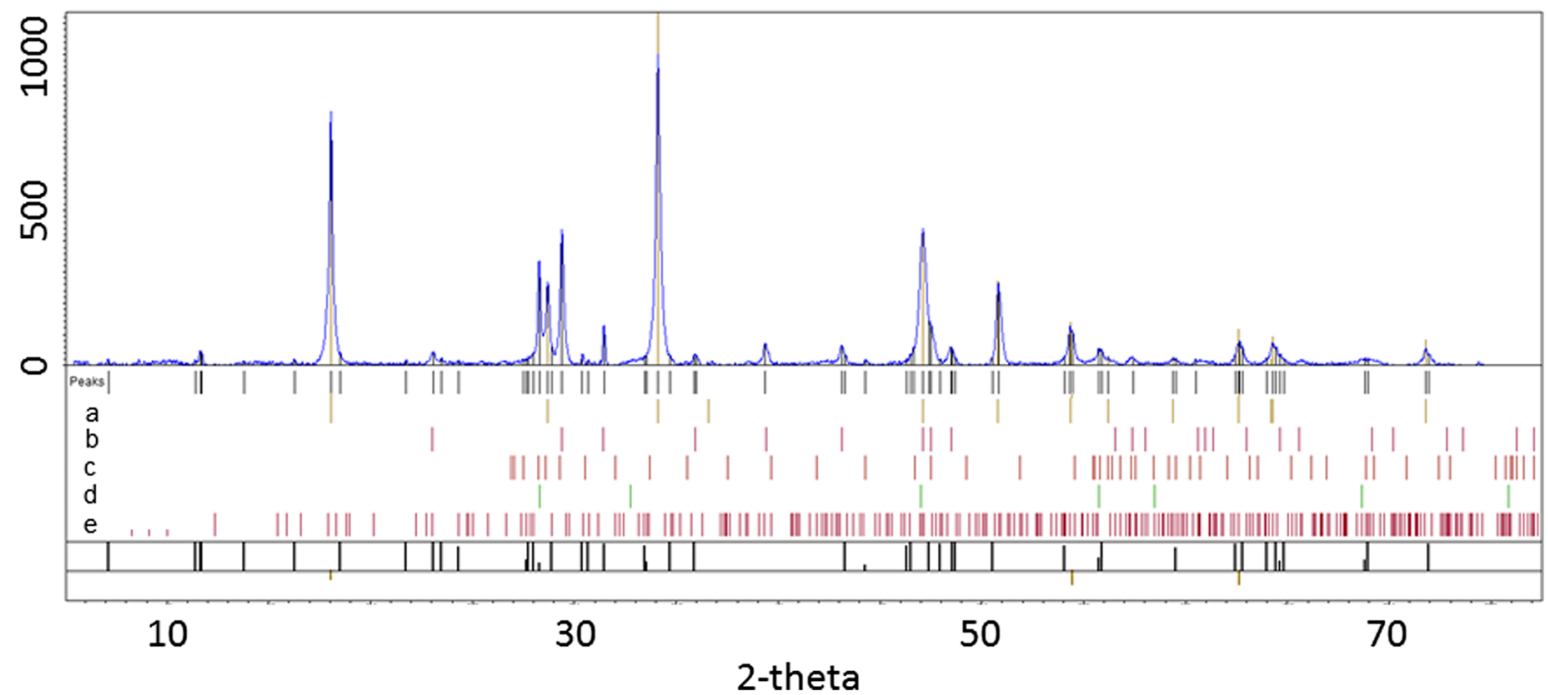

Fig. 8 Flue dust (FD) sample. Contains a. portlandite $(\mathrm{Ca}(\mathrm{OH}) 2)$, b. calcite, c. wurtzite, d. fluorite, e. ettringite

calcium aluminate phase, chromite and another Fe oxide and glass - which is likely to be calc-silicate "slag" material, e.g. Ettringite (Mindat.org 1993-2016; RRUFF 2016). This can be compared to the residual spectrum (Fig. 9) that firstly shows much lower intensities for those peaks present and no identified phases observed.

By using this analysis to follow each extraction step, it was found that fluorite disappears after the 1st extract, the removal of Calcite was observed after the 3rd extraction and the amorphous and crystalline Fe-Mn oxides were not detectable in this process and therefore cannot be confirmed. The loss of sphalerite after the extraction step 6 was also observed, confirming successful extraction of sulphide phases.

The mineralogical identifications made from the raw filter cake (FC) and extraction residue fraction (taken after the 6th extract) are shown in Figs. 10 and 11.

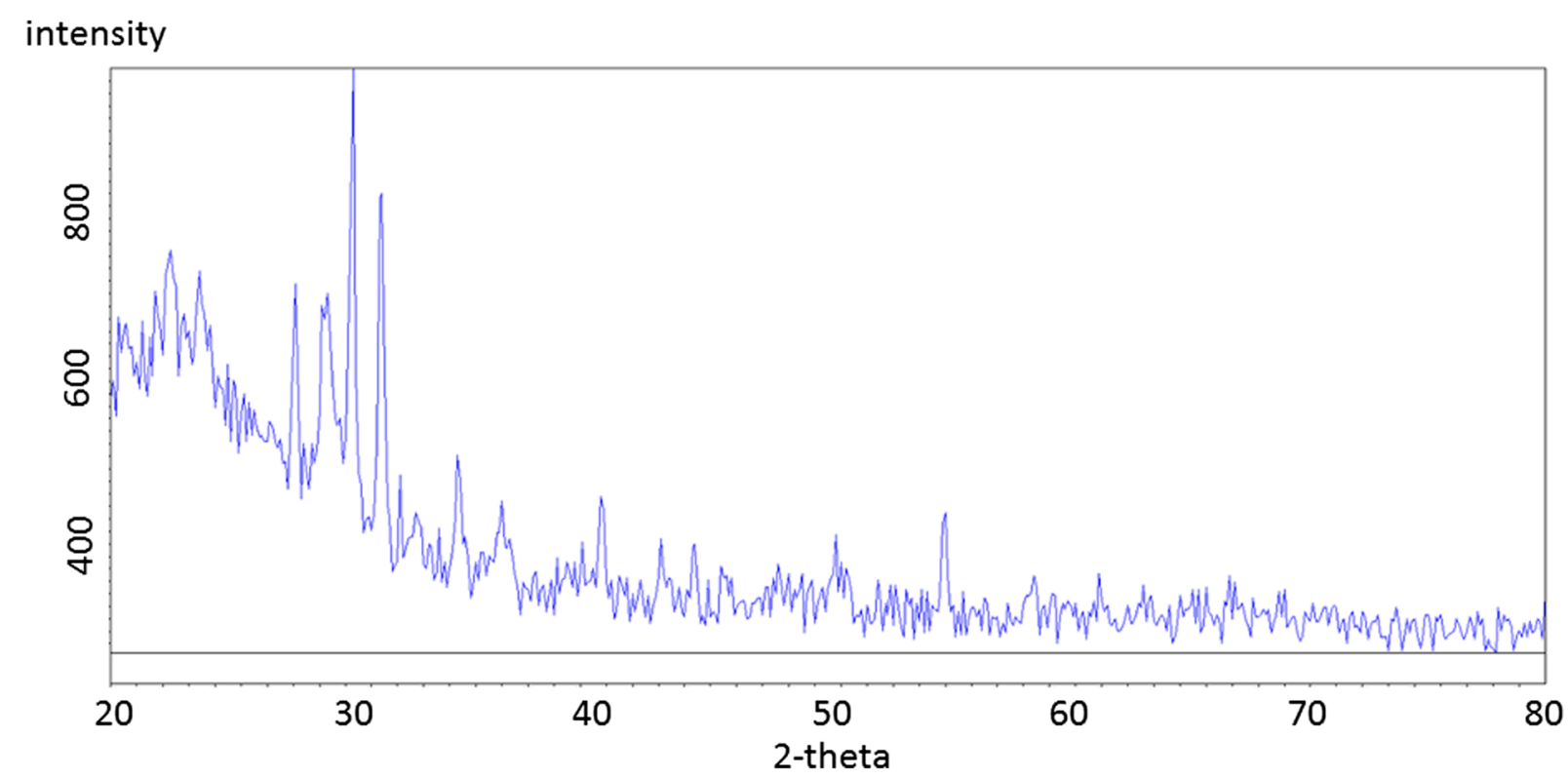

Fig. 9 Residual flue dust (FD). Containing sodium chlorate and Ca-aluminate, the latter being the only likely residue from the starting material 


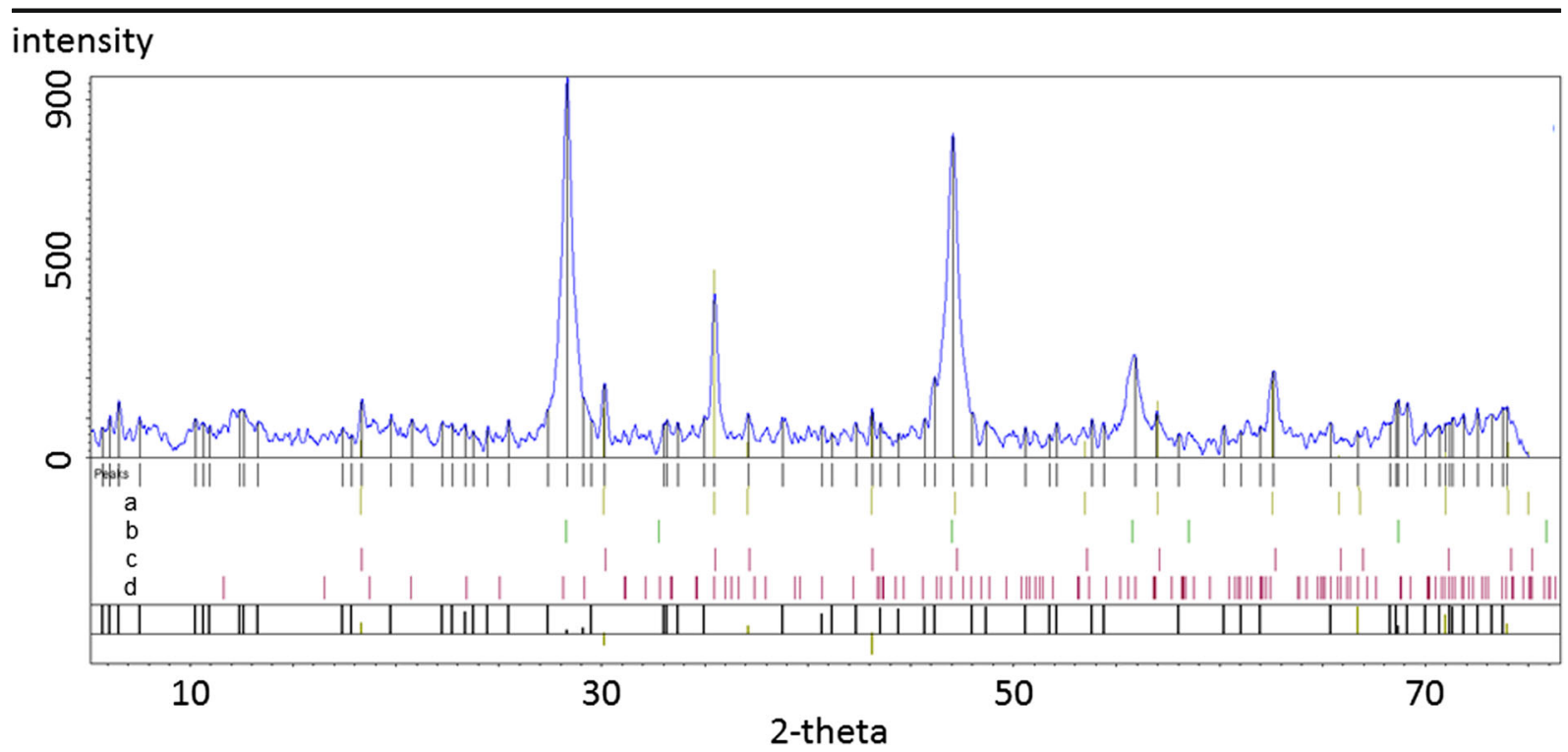

Fig. 10 Filter cake (FC) sample. Contains a. magnetite, b. fluorite, c. chromite, d. gypsum

As with flue dust, FC samples were prepared and analysed using PXRD, and the QualX software identified major phases to be fluorite and iron oxides or hydroxides, with chromitic spinels and low percentages of Ca-sulphate and Ni-sulphides. The chromite fragments are aggregates with either pores or an interstitial Ca phase, most likely calc-silicate glass.

When looking at the solid residues from separate extracts, the success of the extraction procedures was confirmed by changes in the phases identified in material from each step.

The Fe-oxide "magnetite" identified as present in the first four extracts, but after the crystalline oxide extraction (step 4), it was no longer detected. This is also observed with the loss of "sphalerite" after the sulphide extraction step 6. Although there are relatively few phases directly identified by XRD analysis, the loss of components from the diffraction pattern with peak

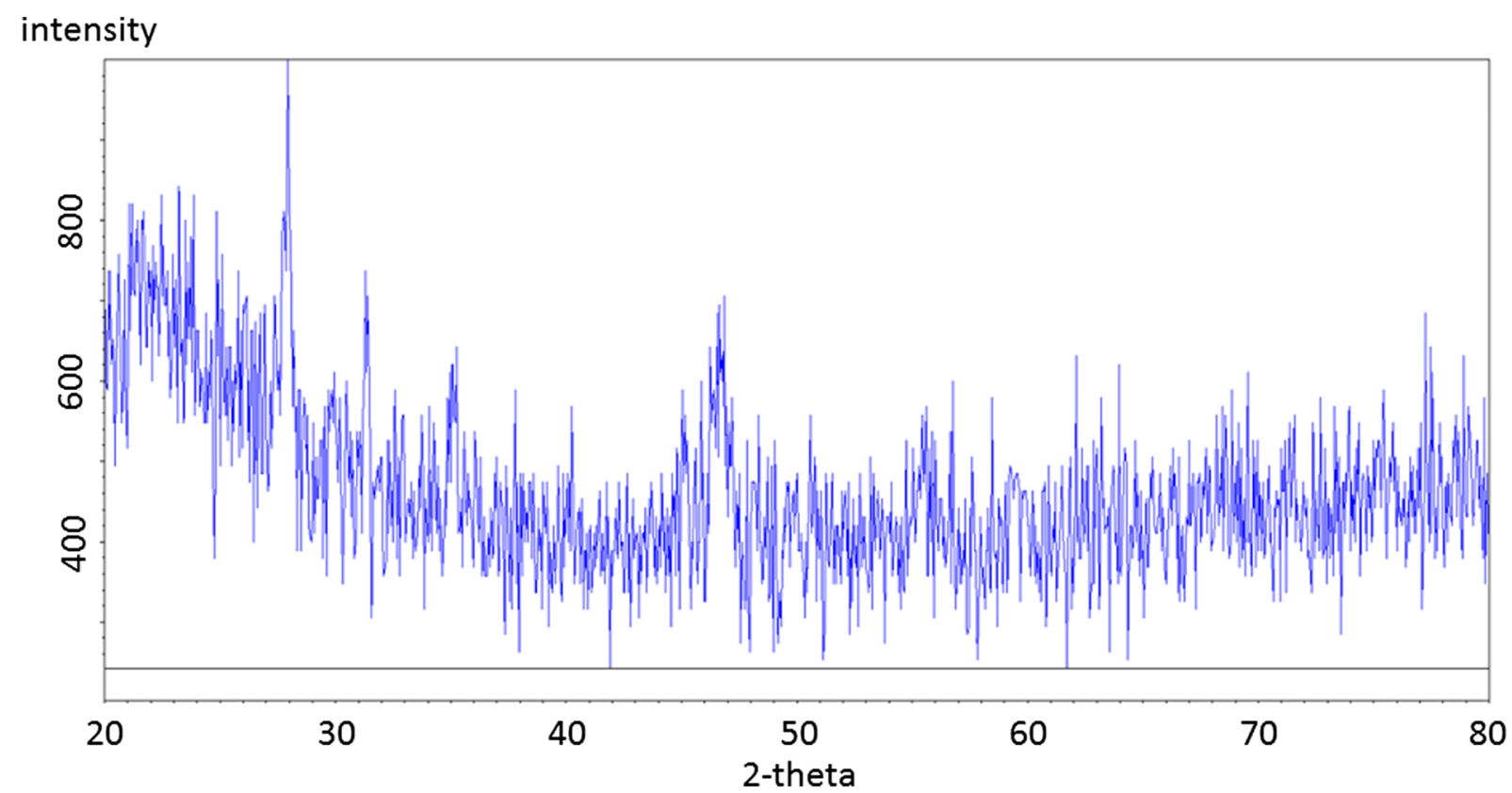

Fig. 11 Residual filter cake (FC). Containing only silicates and oxides 
assignments, demonstrates that the impact of extraction agents on the solid phases follows protocol as designed. However, it is important to remember that their complete dissolution cannot be confirmed due to the limit of detection $(\sim 3 \%)$ for this analytical method (P-XRD).

\section{Scanning electron microscopy-energy-dispersive X-ray spectroscopy}

SEM-EDX (energy-dispersive X-ray spectroscopy) analysis was performed on the residues of the various extracts for both FD and FC samples using a "gunshot residue approach" (Zeichner and Levin 1993); this approach simply uses tape that residual powder sticks too. The residual flue dust samples were too difficult to analyse due to their fine particulate, small quantity and its nature to be easily charged and subsequently lost in analysis.

Flue dust

A general background was determined for FD residues using SEM-EDX (Fig. 12). A wide-area sum spectrum shows one very large peak for Ca with the next largest for $\mathrm{O}$, with possible minor peaks for $\mathrm{Al}, \mathrm{F}, \mathrm{Mg}, \mathrm{Na}, \mathrm{S}$, $\mathrm{Si}, \mathrm{Fe}, \mathrm{K}$ and $\mathrm{Cl}$. EDX maps show that $\mathrm{Ca}$ is present throughout most of the sample; it has much lower pixel density in some larger, elongated, irregular-shaped particles that are enriched in $\mathrm{Al}$, as well as seen in calcium silicate particles. The pale grey angular fragments and rare ovoid pale objects are a $\mathrm{Ca}+\mathrm{F}$ compound (fluorite $\mathrm{CaF}_{2}$ ) and small, BSE-bright particles indicative of $\mathrm{Fe}$ with some rich in $\mathrm{Cr}$.

It can be inferred that the finer particulate offers a greater homogenous mixture as sulphur can be seen in its background but not in the filter cake. It can be concluded that larger sample sizes would be needed in order to utilise SEM as an applicable technique for its analysis.

\section{Filter cake}

The filter cake general background for all the extracts have been determined and shown in Figs. 13 and 14. Here for the first three extracts, it can be observed that the amount of silicon decreases along with the oxygen throughout the extraction steps (Fig. 13); this reduction can be attributed to the initial addition of Si gel from the first step, whereas the consistent peak after step 3 is likely to be representative of sample silica. It can also been observed that $\mathrm{Na}$ appears in the second two extracts as a result of the sodium acetate extraction reagent. The overall elemental matrix shows to be consistent throughout.

The 4th, 5th and 6th extracts are where more noticeable differences occur (Fig. 14). All samples where run in the same session; therefore, the intensity of these peaks can be comparable in terms of concentration inferences. Therefore, it can be stated that the general background remains the same but decreases in concentration chronologically. It is worth nothing that spot analysis was carried out on each extract with sulphur being found with the exception of the 6th extract, which is indicative of successful removal of sulphides.

\section{Fourier transform infrared spectroscopy}

FTIR was used to identify specific functional groups/ bonding present in the samples that may be characteristic of the phases being "extracted". For example the removal of carbonates would be seen by the reduction of the $\mathrm{C}-\mathrm{O}$ and $\mathrm{C}=\mathrm{O}$ signals. By re-evaluating after each extraction has taken place, it can also be used as a confirmatory tool to the success of the extraction procedure and specificity of the reagents used. It is also important to recognise that FTIR identifies bond relationships and cannot identify specific phases, adding information to the development of phase model for the samples. It has been used widely in inorganic and mineralogical analysis (Chen et al. 2015). The analysis of the FTIR was between 600 and $4000 \mathrm{~cm}^{-1}$; however, the transmittance for both FD and FC samples does not alter after $2000 \mathrm{~cm}^{-1}$ and therefore is not shown here.

Flue dust

The residues from each sequential extraction step were air-dried and subjected to FTIR analysis; the corresponding spectra obtained are seen in Fig. 15. It shows the changes in transmittance after each extract where 16 refers to the different extractions, i.e. 1 -water soluble, 2-ion exchangeable, 3 - carbonate, 4-Fe oxides (amorphous), 5-Fe oxides (crystalline) and 6sulfides.

It can be noted in Fig. 15 that clear trends are harder to identify as each extraction takes place. The initial extracts show a variety of $\mathrm{C}-\mathrm{H}$ and $\mathrm{C}-\mathrm{C}$ stretching bands $\left(1420 \mathrm{~cm}^{-1} \mathrm{CH}_{2} ; 1566 \mathrm{~cm}^{-1} \mathrm{C}-\right.$ 


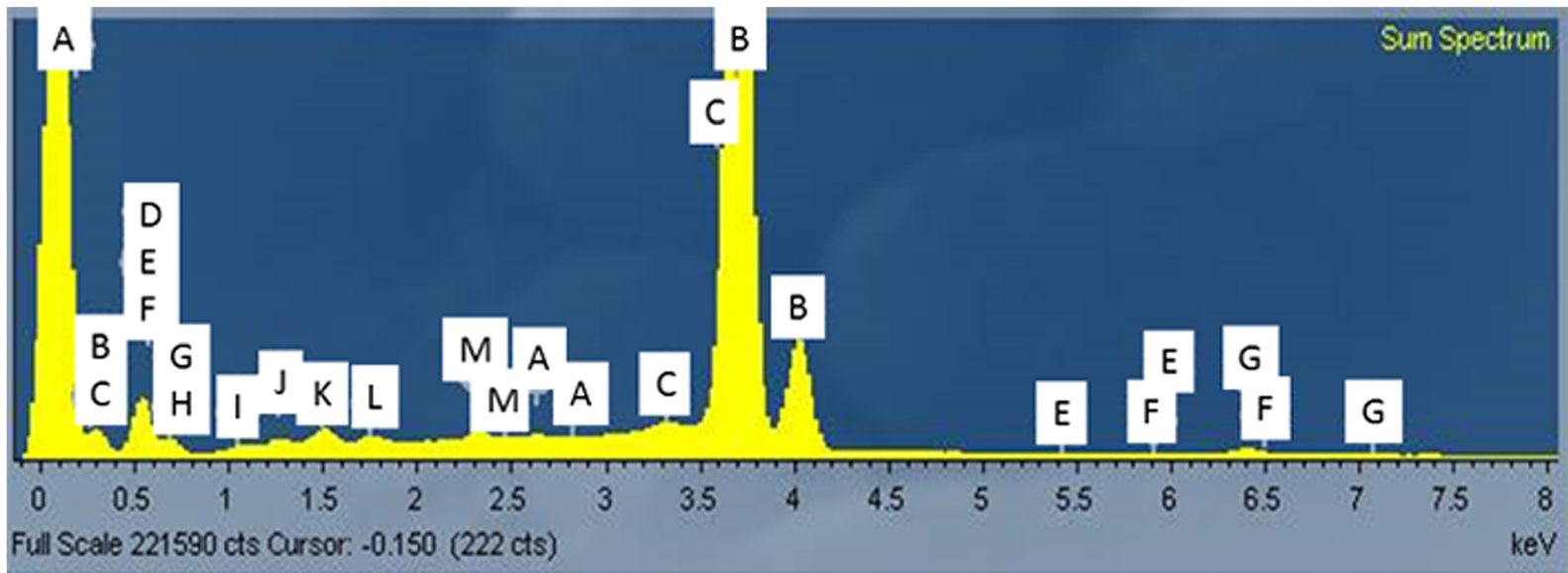

Key

$\mathrm{A}=\mathrm{Cl} ; \mathrm{B}=\mathrm{Ca}, \mathrm{C}=\mathrm{K}, \mathrm{D}=\mathrm{O} ; \mathrm{E}=\mathrm{Cr} ; \mathrm{F}=\mathrm{Mn} ; \mathrm{G}=\mathrm{Fe} ; \mathrm{H}=\mathrm{F} ; \mathrm{I}=\mathrm{Na} ; \mathrm{J}=\mathrm{Mg} ; \mathrm{K}=\mathrm{Al} ; \mathrm{L}=\mathrm{Si} ; \mathrm{M}=\mathrm{S}$
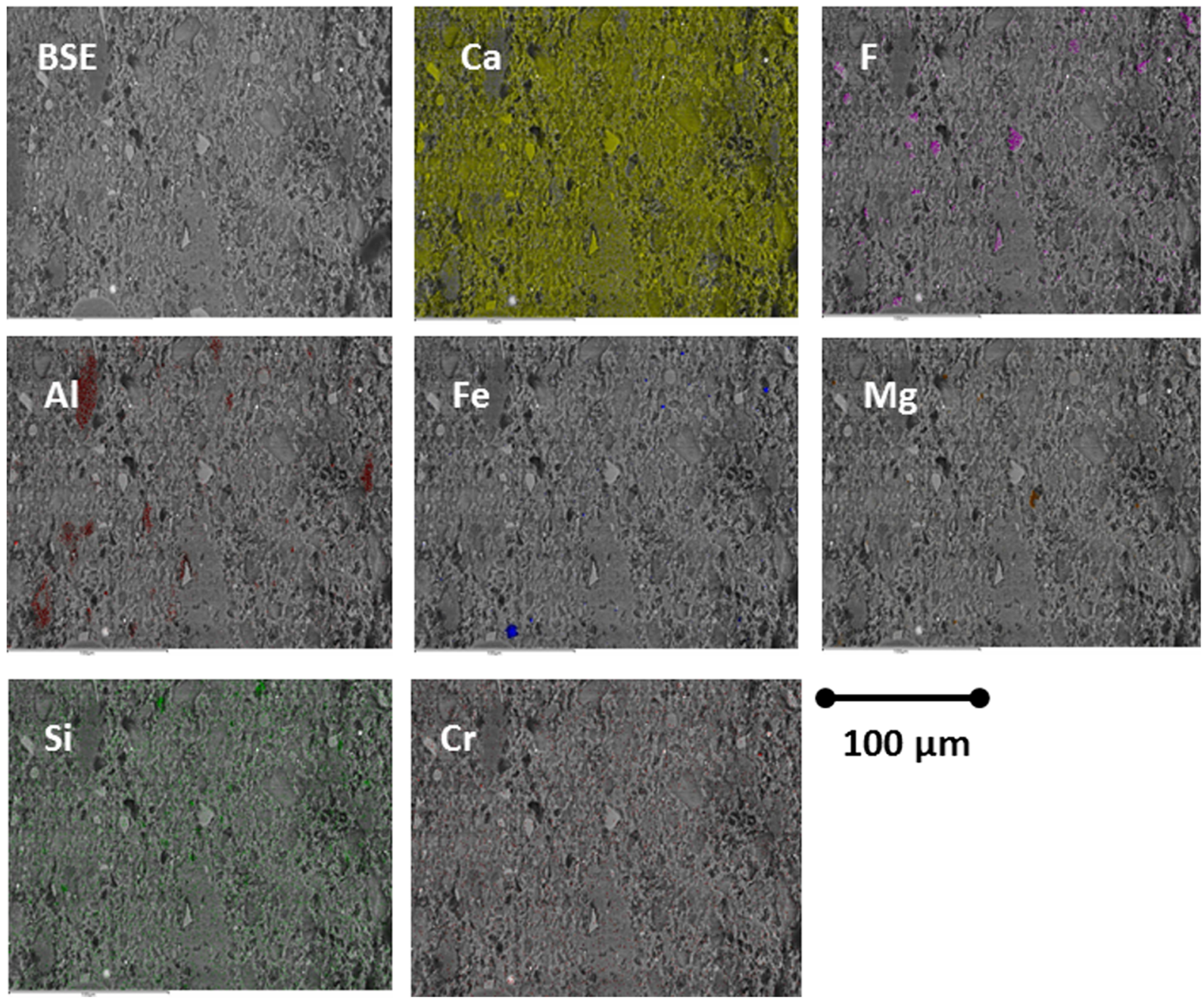

Fig. 12 SEM EDX spectrum and elemental maps of raw FD sample 


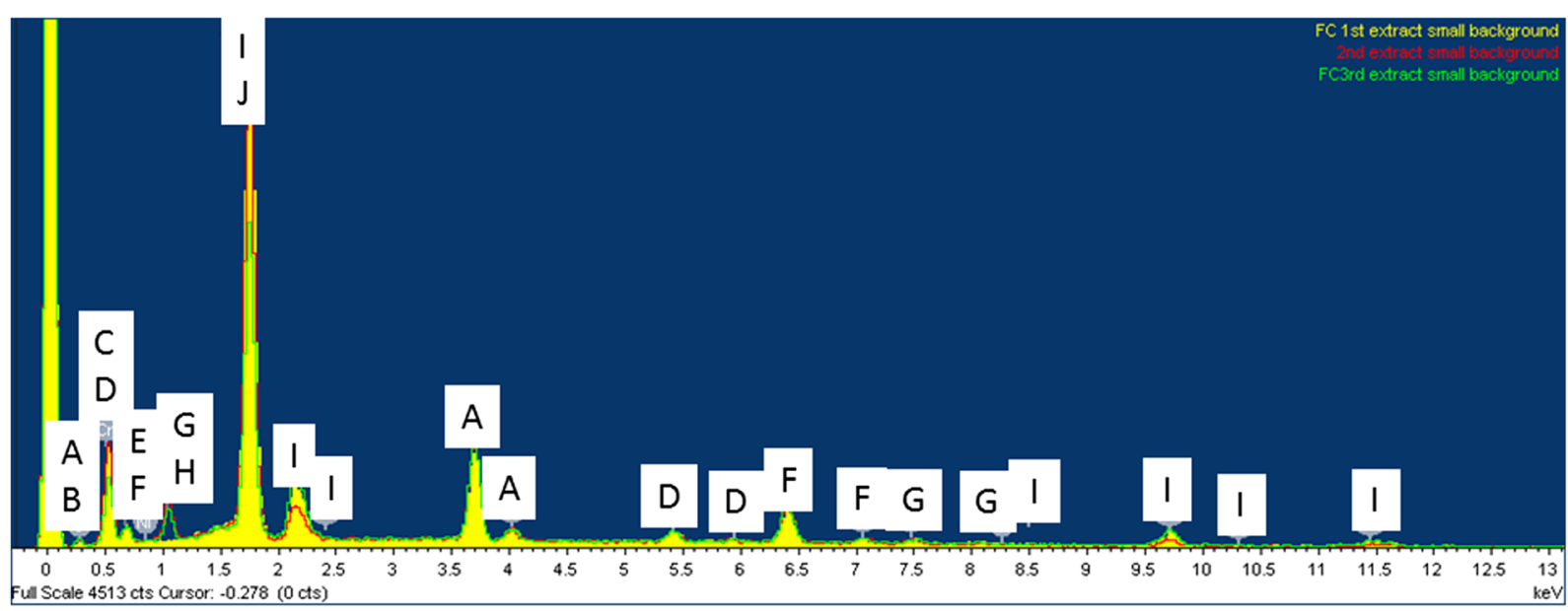

Key

$\mathrm{A}=\mathrm{Ca} ; \mathrm{B}=\mathrm{C}, \mathrm{C}=\mathrm{O}, \mathrm{D}=\mathrm{Cr} ; \mathrm{E}=\mathrm{F} ; \mathrm{F}=\mathrm{Fe} ; \mathrm{G}=\mathrm{Ni}$;

$\mathrm{H}=\mathrm{Na} ; \mathrm{I}=\mathrm{Au} ; \mathrm{J}=\mathrm{Si}$;

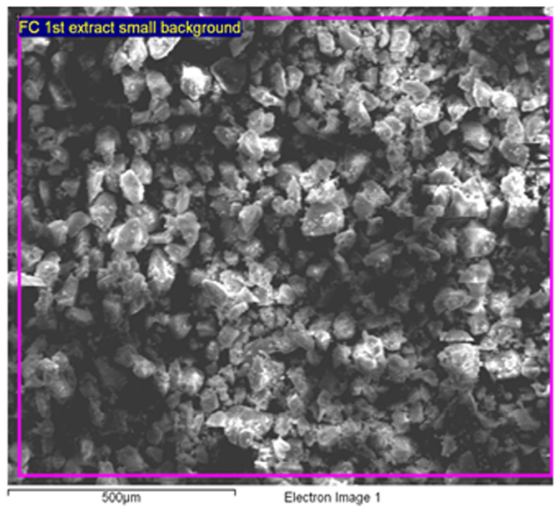

Fig. 13 SEM EDX spectra of FC residues from the first three extracts with backscatter image of bulk sample

C), which could be linked to coke added during the steel production process. The addition of sodium acetate and acetic acid, as extraction reagents, may have added signal to the IR spectrum through contamination as samples were not washed between steps to minimise losses. They were noticeably absent after the 4th extract, i.e. when organic reagents were no longer being used.

The observed peak at $1050 \mathrm{~cm}^{-1}$ could be indicative of $\mathrm{C}-\mathrm{O}$ primary bonds or additional $\mathrm{C}-\mathrm{C}$ bands, which can be linked to graphite (National institute of Standards and technology 2016) and consequently coke (Speight 2015). This C-based complex reacts with oxygen under a gas-solid reaction that occurs with two distinct steps: adsorption of molecular oxygen and surface diffusion of the oxygen molecules. These reactions can be seen below: There are numerous complex reactions between oxygen and carbon, depending on the temperature regime and stage of the batch process giving rise to changes in the dust composition.
Graphite undergoes this reduction to form species such as $\mathrm{O}_{2}{ }^{-}$, or $\mathrm{O}_{2}{ }^{2-}$ until it finally makes stable covalent bonds with carbon atoms (Ulbricht et al. 2002). Due to the low reactivity of graphite, this can explain its lack of removal before the final digestion step and continuous $\mathrm{C}-\mathrm{O}$ liberation and subsequent identification.

The combination of peaks at $1050 \mathrm{~cm}^{-1}$, $1200 \mathrm{~cm}^{-1}$ and $800 \mathrm{~cm}^{-1}$ (which can be seen from the 5th and 6th extracts) is indicative of silica containing complexes (Launer and Arkles 2013; Smith 1960; Sayed and Zeedan 2012; Müller et al. 2012) and would explain their stability during extraction. The glassy matrix identified in the P-XRD is likely to contain Si phases, whilst not directly identified by distinct diffraction lines. These bond associations can be seen after the removal of more prominent peaks, i.e. $\mathrm{CH}_{2}$ from the first two extracts. Other spectroscopic technique such as Raman spectroscopy might reveal fingerprint details and allow interpretation for $\mathrm{Si}$ and metal containing compounds. For example for 


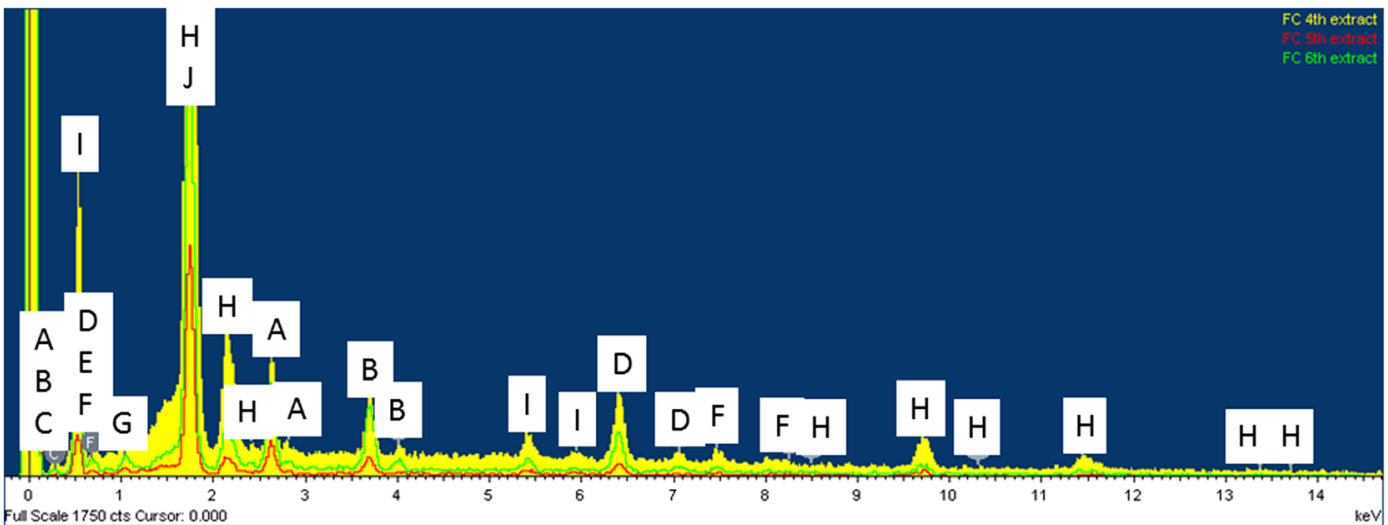

Key

$\mathrm{A}=\mathrm{Cl} ; \mathrm{B}=\mathrm{Ca}, \mathrm{C}=\mathrm{C}, \mathrm{D}=\mathrm{Fe} ; \mathrm{E}=\mathrm{F} ; \mathrm{F}=\mathrm{Ni} ; \mathrm{G}=\mathrm{Na}$;

$\mathrm{H}=\mathrm{Au} ; \mathrm{I}=\mathrm{Cr} ; \mathrm{J}=\mathrm{Si}$;

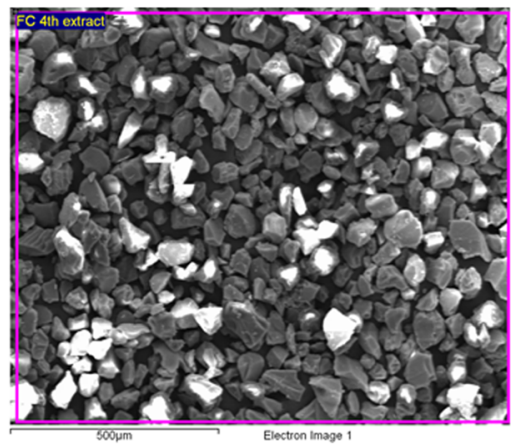

Fig. 14 SEM EDX spectra of FC residues from the 4th, 5th and 6th extracts with backscatter image of bulk sample

absorbance at $540 \mathrm{~cm}^{-1}$, the confirmation of $\mathrm{Si}-\mathrm{O}-\mathrm{Si}$ (quartz) could be made (Balachandran 2014). The sharp absorption in the FTIR observed around $870 \mathrm{~cm}^{-1}$ and smaller peaks around $800-850 \mathrm{~cm}^{-1}$ are also indicative of oxides, which can be seen to reduce in intensity over the extraction steps.

The FTIR analysis does show that the extraction of the carbonate phases and potentially the sulphide phases is successful for both sample types.
Filter cake

Figure 16 shows the changes in transmittance as the filter cake sample is extracted, note that the sulphide (6th) extract is not shown as $100 \%$ present due to no transmittance was observed being detected. The peaks at $1566 \mathrm{~cm}^{-1}$ and $1418 \mathrm{~cm}^{-1}$, again, are indicative of the addition of extraction reagents sodium acetate and acetic acid. The peak around $1050 \mathrm{~cm}^{-1}$ indicates primary $\mathrm{CO}$
Fig. 15 FTIR of flue dust after each of the six extractions

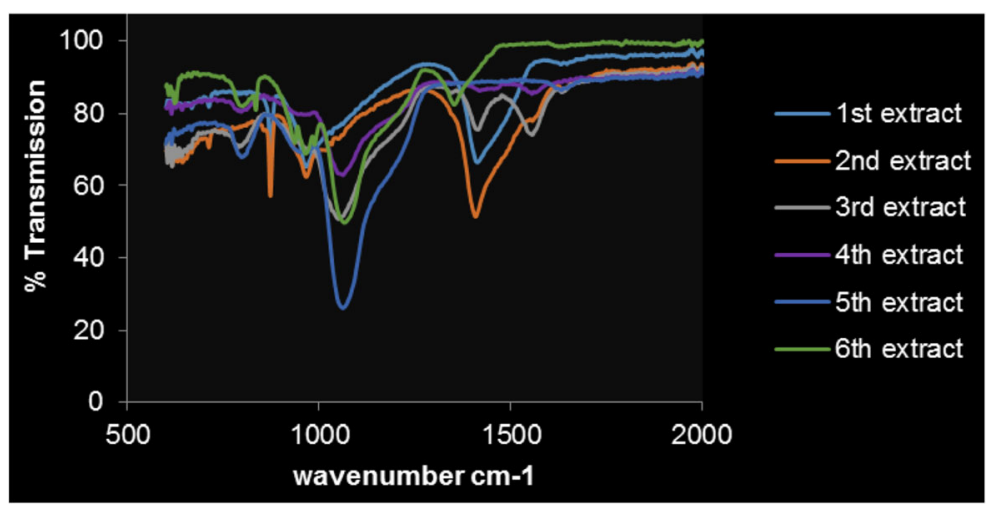




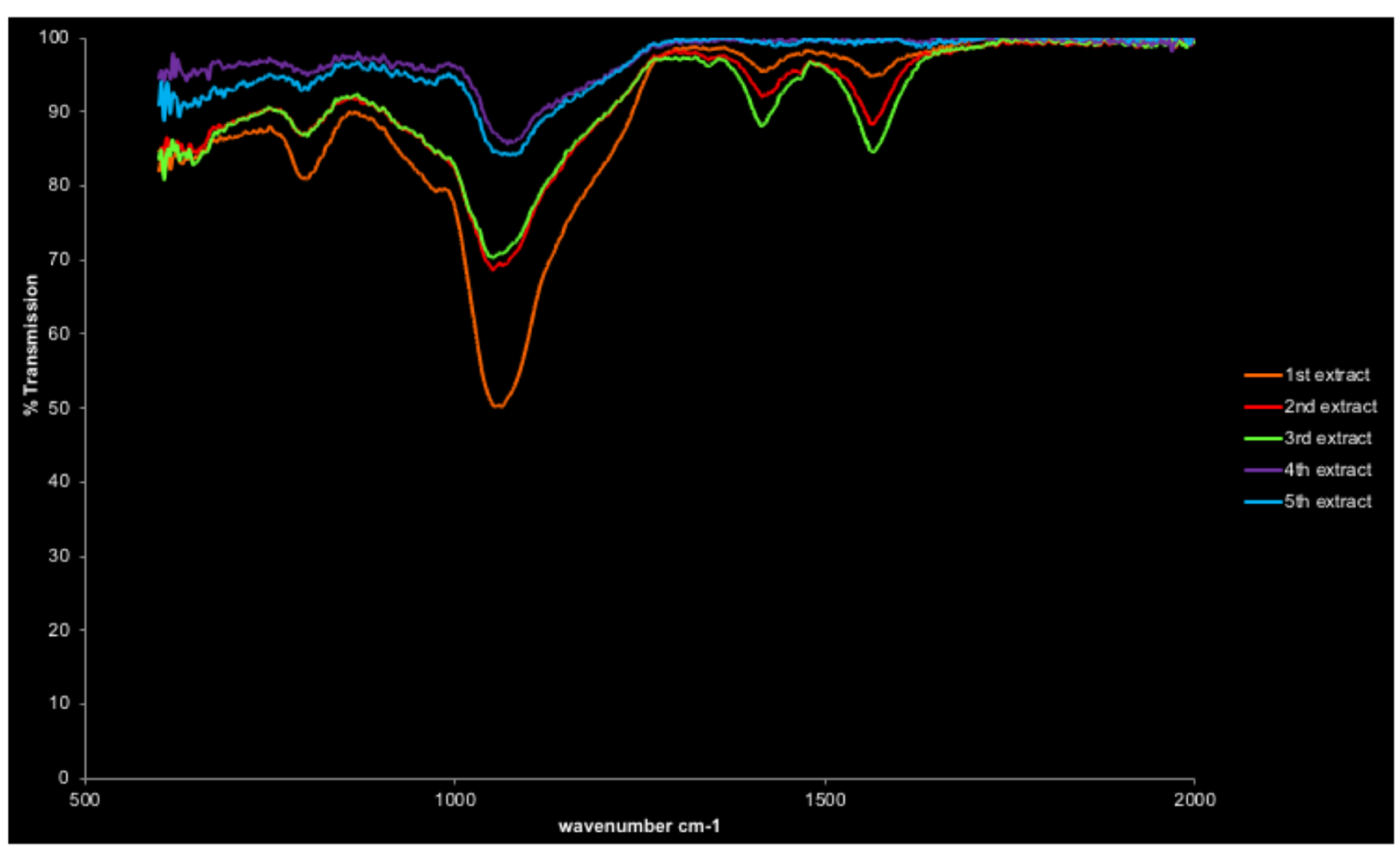

Fig. 16 FTIR of filter cake after each of the first five extractions

bonds, similar to that from the FD sample. Its absence in the 6th extract suggests dissolution is complete.

This is also the case for the $540 \mathrm{~cm}^{-1} \mathrm{Si}-\mathrm{O}-\mathrm{Si}$ stretch for quartz, as although the corresponding peak cannot be measured, unlike the FD samples, its presence disappears by the 6th extract. It is possible this continuous peak represents a SO sulfoxide bond, and confirmation peaks would be found in the "fingerprint" region (below $600 \mathrm{~cm}^{-1}$ ) and therefore are difficult to confirm using this type of analysis. This peak is observed to reduce over the initial extraction steps but disappears by the 6th extract. The sulfoxide signatures are likely to be derived from the oxidation of sulphides, and their presence could be a result of desulphurisation during steel production and sulfide oxidation by the extraction reagents. The bonds are short-range bonds (Pauling 1948; Calligaris 2004), with pseudo-crystalline structures and unable to be identified with the other analytical techniques. The weak peak around the $800 \mathrm{~cm}^{-1}$ region is indicative of the presence of oxides and decreases throughout the extraction steps as the sample matrix is decomposed.

The solid-phase analysis (SPA) performed on sacrificial residual solid samples from SE steps was able to highlight the removal of some phases: carbonates specifically using FTIR analysis and sulphides using XRD and SEM in FC samples. XRD analysis also confirms the successful removal of crystalline Fe-Mn oxide.

\section{Conclusions}

This study has confirmed that the application of a sevenstep sequential extraction method for steel industry process by-products provides phase association data for potentially toxic elements of environmental and process concern. It is able to selectively extract important host phases and can allow an analyst to characterise potentially toxic elements within the waste gaining more detailed knowledge of the reactivity and potential classification. There are however a number of considerations and recommendations:

1. The waste material used in the assessment (flue dust and filter cake) are inherently fine grained and the results have shown a high variability between extraction replicates. It is believed that this is most likely to be caused by the extreme distribution of elements between component phases within the material (i.e. some oxide, metallic phases, carbonate and sulphide components. The heterogeneous 
nature is difficult to overcome, and the analyst must take this into consideration for industrial application the maximum sample size, determined by vessel volumes to preserve extraction solid/solution ratios, that needs to be used.

2. The traditional BCR procedure for environmental matrices involves three overnight shaking periods to ensure that the reaction is complete (Bacon and Davidson 2008). The procedure detailed in this paper have been modified and adapted from previous studies (Leinz et al. 2000) with shorter contact times $(0.5-2 \mathrm{~h})$. Whilst this is "short" for liquid solid reactivity, it is within the legislative requirements of exposure time being no more than $24 \mathrm{~h}$. In addition, the conditions used within this experiment (e.g. concentrated acids and bases) are not what would be encountered in under "real-life" exposure, i.e. acid rain leaching. It is our recommendation therefore that short exposure times are used; however, the analyst must consider that a small fluctuation, e.g. 5-10 min at 30-min exposure, represents an additional $20-30 \%$ increase in contact time and subsequent influence on elemental extraction.

3. It has been shown that sequential extraction (SE) can successfully apportion elements to specific phases. If this is combined with the pseudo-total data, then fuller predictions can be made about the elemental composition of steel waste. For example, $\mathrm{Cr}$ in the filter cake had a total concentration of approx. $26,000 \mathrm{mg} / \mathrm{kg}$ with $14.4 \%$ found within the carbonate (3rd step) most likely as $\mathrm{Cr}_{2}\left(\mathrm{CO}_{3}\right)_{3}$. Although SE does not give a complete mineralogical identification, it provides sufficient information about an element's most likely host phase allowing factors that could be used to promote release from waste (e.g. for recovery and re-use) and/or predict environmental impact and subsequent classification as hazardous or non-hazardous waste.

4. This information could be used as a useful environmental indicator related to current Waste Acceptance Criteria (WAC) regulatory testing European Commission 2009). Using $\mathrm{Cr}$ as an example, the water soluble fraction (1st extract) of the filter cake had a median concentration of $9.1 \mathrm{mg} / \mathrm{kg}$; under WAC thresholds, this would be categorised as nonhazardous waste (even if the high replicate variation was taken into account) as it is below the $70 \mathrm{mg} / \mathrm{kg}$ threshold (Environment Agency 2013). The content in the carbonate phase however could be considered hazardous as the portion contained in this phase is reactive if introduced to the environment.

This study has shown that sequential extraction (SE) can be considered a low-cost "simple" analytical methodology when compared to the limitations of some instrumental techniques such as X-ray diffraction, Fourier transform infrared spectroscopy and scanning electron microscopy, which provide important feedback on the reactivity of process by products. The use of SE has industry wide implications for application to address concerns about definition of hazardous waste (and identify methods to treat them accordingly). This brings us a step closer to more circular resource management and implications for cost-effective regulatory systems, enhancing environmental compliance.

Open Access This article is distributed under the terms of the Creative Commons Attribution 4.0 International License (http:// creativecommons.org/licenses/by/4.0/), which permits unrestricted use, distribution, and reproduction in any medium, provided you give appropriate credit to the original author(s) and the source, provide a link to the Creative Commons license, and indicate if changes were made.

Publisher's note Springer Nature remains neutral with regard to jurisdictional claims in published maps and institutional affiliations.

\section{References}

Baba, A. A., \& Adekola, F. A. (2010). Hydrometallurgical processing of a Nigerian sphalerite in hydrochloric acid: characterization and dissolution kinetics. Hydrometallurgy, 101, 69-75.

Bacon, J. R., \& Davidson, C. M. (2008). Is there a future for sequential chemical extraction? Analyst, 133, 25-46.

Bacon, J. R., Hewitt, I. J., \& Cooper, P. (2005). Reproducibility of the BCR sequential extraction procedure in a long-term study of the association of heavy metals with soil components in an upland catchment in Scotland. Science of the Total Environment, 337, 191-205.

Balachandran, M. (2014). Role of infrared spectroscopy in coal analysis - an investigation. American Journal of Analytical Chemistry, 5, 367-372.

Besta, P., Janovská, K., Samolejová, A., Beránková, A., Vozňáková, I., \& Hendrych, M. (2013). The cycle and effect of zinc in the blast-furnace process. Metalurgija, 52, 197-200.

Besta, P., Samolejová, A., Lenort, R., Janovská, K., Kutáč, J., \& Sikorová, A. (2014). Alkaline carbonates in blast furnace process. Metalurgija, 53, 549-552. 
Calligaris, M. (2004). Structure and bonding in metal sulfoxide complexes: an update. Coordination Chemistry Reviews, 248, 351-375.

Cantario, M. V., Filho, C. D. C., \& Mansur, M. B. (2012). Selective removal of zinc from basic oxygen furnace sludge. Hydrometallurgy, 111-112, 124-128.

CEWEP. (2012). Landfill taxes \& bans. Confederation of European Waste-to-Energy Plants.http://www.cewep.eu/media/www. cewep.eu/org/med_557/955_2012-04-27_cewep_-_landfill_ taxes_bans_website.pdf. Accessed 10 Oct 2017

Chen, Y., Zou, C., Mastalerz, M., Hu, S., Gasaway, C., \& Tao, X. (2015). Applications of micro-Fourier transform infrared spectroscopy (FTIR) in the geological sciences - a review. International Journal of Molecular Sciences, 16(12), 3022330250 .

Cointreau, S. (2008). Landfill ER Revenue versus Landfill costs. 2018 , from http://siteresources.worldbank. org/INTUWM/Resources/340232-1208964677407 /Cointreau.pdf. Accessed 10 Oct 2018.

David, J. A. \& Leventhal, J. S. (1995). Bioavailabilty of metals, chapter 2: Preliminary compilation of descriptive geoenvironmental mineral deposit models. In: Bray, E. A. D. (ed.). U.S. Denver: Department of the interior U.S. Geological Survey.

Environment Agency. (2013). Waste sampling and testing for disposal to landfill. England: Environment Agency.

European Commission, B. (2009). Assessing legal compliance with and implementation of the waste acceptance criteria and procedures by the EU-15. 07.0307/2008/510910/SER/G4.

Filgueiras, A. V., Lavilla, I., \& Bendicho, C. (2002). Chemical sequential extraction for metal partitioning in environmental solid samples. Journal of Environmental Monitoring, 4, 823857.

Inorganic Ventures. (2016). Interactive periodic table [Online]. Virginia. Available: http://www.inorganicventures. com/periodic-table. Accessed September 2017.

IUPAC. (2017). Compendium of Chemical Terminology Gold Book. https://goldbook.iupac.org/pages/about.html. Accessed 25th January 2019.

Launer, P. J. \& Arkles, B. (2013). Silicon compounds: Silanes \& Silicones edition: 3rd chapter. In Arkles, B., Larson, G. L. (Eds.), Infrared Analysis of Organosilicon Compounds Publisher: Gelest Inc. https://www.gelest.com/wp-content/uploads/5000 A_Section1_InfraredAnalysis.pdf. Accessed 10 Oct 2017.

Lee, J. D. (1999). Concise inorganic chemistry. Oxford: Blackwell Science Ltd.

Leinz, R. W., Sutley, S. J., Desborough, G. A. \& Briggs, P. H. (2000). An investigation of the partitioning of metals in mine wastes using sequential extractions. ICARD 2000: Proceedings from the fifth international conference on acid rock drainage volume II. Society for Mining, Metallurgy, and Exploration.

Maul, G. A., Kim, Y., Amini, A., Zhang, Q., \& Boyer, T. H. (2014). Efficiency and life cycle environmental impacts of ion-exchange regeneration using sodium, potassium, chloride, and bicarbonate salts. Chemical Engineering Journal, 254, 198-209.

Mindat.org. (1993-2016). Mineralogical database. Hudson Institute of mineralogy. http://www.mindat.org/. Accessed 10 Oct 2017.
Müller, C. M., Molinelli, A., Karlowatz, M., Aleksandrov, A., Orlando, T., \& Mizaikoff, B. (2012). Infrared attenuated total reflection spectroscopy of quartz and silica micro- and nanoparticulate films. The Journal of Physical Chemistry $C$, 116, 37-43.

National Institute of Standards and Technology. (2016). Acetic acid, sodium salt. http://webbook.nist.gov/cgi/cbook. cgi? ID=B6005784\&Mask=80. Accessed 10 Oct 2017.

Pauling, L. (1948). The modern theory of valency. Journal of the Chemical Society (Resumed), 1461-1467.

Prudent, P., Domeizel, M., \& Massiani, C. (1996). Chemical sequential extraction as decision-making tool: application to municipal solid waste and its individual constituents. The Science of the Total Environment, 178, 55-61.

Rodgers, K. J., Hursthouse, A., \& Cuthbert, S. (2015). The potential of sequential extraction in the characterisation and management of wastes from steel processing: a prospective review. International Journal of Environmental Research and Public Health, 12, 11724-11755.

RRUFF. (2016). Integrated database of Raman spectra, X-ray diffraction and chemistry data for minerals. http://rruff.info/. Accessed 10 Oct 2017.

Sayed, M., \& Zeedan, S. R. (2012). Green binding material using alkali activated blast furnace slag with silica fume. $H B R C$ Journal, 8, 177-184.

Smith, A. L. (1960). Infrared spectra-structure correlations for organosilicon compounds, Spectrochimica Acta, 16(1), 87-105.

Speight, J. G. (2015). Coke, carbon black, and graphite. In M. Viitha (Ed.), Handbook of petroleum product analysis (2nd ed., pp. 285-295). Hoboken: John Wiley \& Sons, Inc.

Suryanarayana, C., \& Norton, M. G. (1998). X-ray diffraction: a practical approach. New York: Springer Science + Business Media Ltd.

Tessier, A., Campbell, P. G. C., \& Bisson, M. (1979). Sequential extraction procedure for the speciation of particulate trace metals. Analytical Chemistry, 51, 844-850.

The International Centre for Diffraction Data. (1997-2015). ICDD Database. JCPDShttp://www.icdd.com. Accessed 10 Oct 1017.

Todorov, T. I., Wolf, R. E., \& Adams, M. (2014). Multi-elemental analysis of aqueous geological samples by inductively coupled plasma-optical emission spectrometry. Virginia: U. S Geological Survey.

Uçar, G. (2009). Kinetics of sphalerite dissolution by sodium chlorate in hydrochloric acid. Hydrometallurgy, 95, 39-43.

Ulbricht, H., Moos, G., \& Hertel, T. (2002). Physisorption of molecular oxygen on single-wall carbon nanotube bundles and graphite. Physical Review B, 66, 075404.

Weil, R. R., \& Brady, N. C. (2016). Nature and properties of soils. Pearson Education, Inc.

World Steel Association. (2014). Steel industry by-products [Online]. Available: http://www.worldsteel.org/publications/factsheets/content/01/text_files/file/document/Fact_Byproducts_2014.pdf. Accessed 10 Oct 2017.

Zeichner, A. \& Levin, N. (1993). Collection efficiency of gunshot residue (GSR) particles from hair and hands using doubleside adhesive tape. Journal of Forensic Sciences, 38(3), 571584.

Zhan, G. \& Guo, Z. (2013). Basic properties of sintering dust from iron and steel plant and potassium recovery. Journal of Environmental Sciences, 25(6), 1226-1234. 